\title{
LA OPERACIÓN LIBERTAD DURADERA Y LA LEGÍTIMA DEFENSA A LA LUZ DE LOS ATENTADOS DEL 11 DE SEPTIEMBRE DE 2001
}

\author{
José B. Acosta EstÉveZ*
}

RESUMEN: Después de los ataques del 11 de septiembre parecía que había llegado el momento del multilateralismo y la hora de reforzar el papel de las Naciones Unidas, pues los Estados Unidos de América habrían podido liderar el sistema multilateral, cuyo eje es la ONU, frente al terrorismo, pero la realidad es otra muy distinta: la postura estadounidense ha acentuado el unilateralismo exhibido durante los últimos tiempos con el fin de satisfacer sus intereses o combatir las amenazas a su seguridad, utilizando para ello, tras la faz de la legítima defensa, la figura de la defensa preventiva.

ABSTRACT. After the attacks of the 11th of September, it seemed that the moment for multilateralism and the reinforcement of the role of the United Nations had arrived, with the U.S. leading the multilateral system in the face of terrorism. However the reality is quite different: the United States' posture has emphasized the unilateralism shown in recent times in order to satisfy its interests or combat threats to its security, using, on the pretext of self-defense, the concept of pre-emptive defense.

RÉSUMÉ: Après les attaques du 11 septembre, il semblait que le moment étant venu pour un monde multilatéral, un renforcement du rôle des Nations Unies et dont les Etats-Unis auraient pu être les leaders face au terrorisme. Néanmoins, la réalité est autre. L'attitude des Etats-Unis a accentué le monde unilatéral, attitude servant à satisfaire leurs intérêts ou à combattre ce qui menace sa sécurité, en utilisant pour arriver à ses fins, sous prétexte de légitime défense, le concept de la défense préventive.

* Profesor titular de derecho internacional público y relaciones internacionales.

Anuario Mexicano de Derecho Internacional, vol. VI, 2006, pp. 13-61 
Todos comprenden el dolor que se relaciona con la muerte, pero el verdadero dolor no está presente en el espíritu. No está en el aire ni en nuestra vida, ni en estas terrazas llenas de humo. El verdadero dolor que mantiene despiertas las cosas es una pequeña quemadura infinita en los ojos inocentes de los otros sistemas.

García Lorca, ${ }^{1}$ Panorama ciego de Nueva York

SUMARIO: I. Introducción. II. La administración Clinton y la operación Alcance Infinito. III. Una fecha que vivirá en la infamia: martes, 11 de septiembre del 2001. IV. La reacción del Consejo de Seguridad. Las resoluciones 1368 (2001) y 1373 (2001). V. La administración Bush y la operación Libertad Duradera. VI. El marco jurídico de la legítima defensa, los atentados del 11 de septiembre y la respuesta estadounidense. VII. La solución "correcta" del "conflicto afgano". VIII. La legítima defensa preventiva como doctrina estratégica de seguridad. IX. El tránsito del multilateralismo autoritario al unilateralismo agresivo. X. Consideraciones finales.

\section{INTRODUCCIÓN}

El derecho sirve para regir la conducta humana, estableciendo el deber ser en un determinado momento ${ }^{2} \mathrm{y}$, por este motivo, el jurista no puede permanecer impávido ante la situación del terrorismo. Así, entre los instrumentos de que el ser humano dispone para evitar el terrorismo internacional, el derecho internacional es uno de los más importantes. A partir del horror por la magnitud de la tragedia del 11 de septiembre algo ha empezado a cambiar en el modo de afrontar la lucha contra el terrorismo desde el derecho

1 García Lorca, F., Poeta en Nueva York, Madrid, 1975, p. 59.

2 Carnelutti, F., Discorsi in torno al Diritto, Padova, 1961, vol. III, p. 30. 
internacional ${ }^{3}$ y las Naciones Unidas. ${ }^{4}$ No obstante, dicho cambio no ha respondido a las expectativas deseadas, pues si bien la decisión del Consejo de Seguridad de "combatir por todos los medios las amenazas a la paz y la seguridad internacionales creadas por actos de terrorismo", Resolución 1368 (2001), y la posterior invocación del capítulo VII de la carta, Resolución 1373 (2001), así como el reconocimiento del derecho a la legítima defensa, Resoluciones 1368 (2001) y 1373 (2001), parecía indicar que, en palabras de Dupuy, ${ }^{5}$ las Naciones Unidas estaban dispuestas a jugar un papel decisivo en la gestión de la crisis, la realidad es que las mismas omitieron sus funciones en relación con el mantenimiento de la paz y seguridad internacionales y, más en concreto, el Consejo de Seguridad se automarginó en el ejercicio institucional del uso de la fuerza armada, ya que ésta no se llevó a cabo en el marco institucional - artículo 42 de la carta - sino por vía de la legítima defensa.

A partir de la Resolución 1368, de 12 de septiembre del 2001, puede advertirse la intención del Consejo de Seguridad de combatir por todos los medios los actos terroristas de cualquier naturaleza que amenacen a la paz y a la seguridad internacionales. Y, en este contexto, el Consejo de Seguridad formula una declaración esencial: el reconocimiento del derecho de legítima defensa individual y colectiva de conformidad con la carta, por un lado, y la calificación de las acciones terroristas del 11 de septiembre como ataques contra los que tomará todas las medidas que sean necesarias, por otro. Posteriormente, la Resolución 1373 (2001) vuelve a reafirmar el derecho de legítima defensa. Y, a partir de estas resoluciones, para algunos autores, como por ejemplo, Bermejo García, las indicadas acciones terroristas son ataques susceptibles de ser englobados

3 Cassese, A., "Terrorism is also disrupting some crucial legal categories of international law”, en European Journal of International Law, 2001, núm. 5, pp. 993 y ss.; Condorelli, L., "Les attentats du 11 septembre et leur suites: où va le droit international?", Révue Générale de Droit International Public, 2001, núm. 4, pp. 829 y ss.; Kovecs, P., "Beaucoup de questions et peu de réponses. Autour de 1'imputabilité d'un acte terroriste à un Etat", Anuario de Derecho Internacional, 2001, vol. XVII, pp. 39 y ss.; Schrijver, N., "Responding to international terrorism: moving the frontiers of international law for "enduring freedom", Netherlands International Law Review, 2001, núm. 3, pp. 271 y ss. Al respecto, el debate en European Journal of International Law (http://www.ejil.org/forum-WTC/ny): Pellet, A., "No, this is not war!", Dupuy, P., "The law after de destruction of the towers", Gaja, G., "In what sense was there an 'armed attack"'; Meget, F., "War? Legal semantics and the move to violence".

4 Al respecto, UNA-USA, A policy report of the United Nations Association of the United States of America. Combating terrirism: does the Un matter... and how, Nueva York, 2002.

5 Dupuy, P., "The law after the destruction of the Towers", European Journal of International Law (http://www.ejil.org/forum-WTC/ny). 
entre los que dan derecho a la legítima defensa según el artículo 51 de la carta; ${ }^{6}$ mientras que para otros, como Gutiérrez Espada ${ }^{7}$ o Remiro Brotóns, ${ }^{8}$ no cabe invocar tal derecho sobre la base de los mencionados actos. Entre estas dos posturas, otros autores, como Pastor Ridruejo, ${ }^{9}$ sostienen que cabe hablar de una agresión indirecta ${ }^{10}$ por parte del Estado afgano, por dar cobijo al grupo terrorista, ${ }^{11}$ pero la objeción que cabe oponer a la acción militar estadounidense como supuesto de ejercicio de legítima defensa, es que la reacción frente a los atentados no fue inminente ni el Consejo de Seguridad adoptó nunca las medidas militares previstas en el artículo 42 de la carta. Por consiguiente, la cuestión a responder es si, frente a los actos terroristas perpetrados el 11 de septiembre, la respuesta de los Estados Unidos de América fue adecuada iSe enmarca la intervención militar estadounidense en el ámbito del derecho de legítima defensa o, por el contrario, se trata de una acción propia de la denominada legítima defensa preventiva?

La búsqueda de la solución a la cuestión planteada requiere tener presente cuestiones tanto jurídicas como políticas. En el plano jurídico, el análisis de las resoluciones 1368 (2001) y 1373 (2001) del Consejo de Seguridad, y el marco legal del derecho de legítima defensa previsto en la Carta de las Naciones Unidas, permitirán determinar, atendiendo a la intervención estadounidense - y sus comparsas británicos-, si la misma fue en aplicación de dicho derecho o, por el contrario, ajena a la legalidad internacional, constituyendo un supuesto de defensa preventiva. Desde la vertiente política, la exposición de los comportamientos de las

6 Bermejo García, R., "El derecho internacional frente al terrorismo: ¿nuevas perspectivas tras los atentados del 11 de septiembre?", $A D I, 2001$, vol. XVII, pp. 10 y 23.

7 Gutiérrez Espada, C., ¿"No cesaréis de citarnos leyes viendo que ceñimos espada? (a propósito del 11-S)", ADI, 2001, vol. XVII, p. 34.

8 Remiro Brotóns, A., "Estados Unidos no se pregunta en qué se equivoca", $P E, 2002$, núm. 85, p. 119.

9 Pastor Ridruejo, J., Curso de derecho internacional público y organizaciones internacionales, Madrid, 2003, pp. 727 y 728

10 "La legalidad de la acción de los Estados Unidos podría basarse en que el ataque armado puede consistir en una agresión indirecta realizada por bandas armadas que cuenten con el apoyo de un Estado; en este caso concreto en el ataque realizado por el grupo terrorista islámico con el apoyo del gobierno de Afganistán. Las referencias al derecho de legítima defensa contenidas en las resoluciones del Consejo de Seguridad y la aprobación de la reacción armada por parte de los países de la Alianza Atlántica, organizaciones internacionales y gran parte de la comunidad internacional equivaldría a una aceptación de esta extensión del derecho de legítima defensa reconocido en la Carta de las Naciones Unidas" (Casanovas y La Rosa, O., "El principio de la prohibición del uso de la fuerza", Instituciones de derecho internacional público, Madrid, 2003, p. 920).

11 Cassese, A., Terrorism..., cit., pp. 993 y ss. 
administraciones Clinton - en tanto que antecedente histórico- y Bush permitirán explicar el por qué esta respuesta de los Estados Unidos de América a los atentados del 11 de septiembre, así como su posicionamiento en la sociedad internacional contemporánea. Como puede advertirse, en la cuestión tratada se interacciona lo político y lo jurídico y, por ello, el desarrollo de este trabajo responde a esta circunstancia, esto es, las páginas que siguen no se han estructurado atendiendo a un apartado netamente jurídico ni otro que contemplara únicamente los aspectos políticos.

\section{LA ADMINISTRACIÓN CLINTON Y LA OPERACIÓN ALCANCE INFINITO}

En febrero de 1998, Osama Bin Laden había emitido una fatwa anunciando ataques armados contra el ejército y objetivos civiles estadounidenses en todo el mundo, repitiéndose este tipo de declaraciones en los meses de mayo y junio. El 7 de agosto de 1998 estallaron dos camiones-bomba en las embajadas estadounidenses de Dar es Salaam (Tanzania) y Nairobi (Kenia) respectivamente, ${ }^{12}$ con cinco minutos de diferencia; mataron a 257 personas, 12 de ellas de nacionalidad estadounidense. ${ }^{13}$ Una semana después, tanto la CIA como el FBI aportaron pruebas detalladas de la operación ${ }^{14} \mathrm{y}$ confirmaron al presidente Clinton que el responsable de los atentados había sido Al Qaeda y que tenía planes para atentar contra la embajada de Estados Unidos de América en Albania. ${ }^{15}$ Asimismo, la CIA informó que Osama Bin Laden y sus lugartenientes tenían previsto reunirse en Afganistán el 20 de agosto "para revisar los resultados de sus ataques y planear la siguiente oleada" ${ }^{16}$ Finalmente, Clinton dijo a los presentes: "escuchad: tomar represalias ante estos ataques está muy bien, pero tenemos que librarnos de estos tipos de una vez por todas. ¿Comprendéis lo

12 Al respecto, Comisión Nacional de Investigación, Informe final de los atentados terroristas contra Estados Unidos, Barcelona, 2005, pp. 90-93.

13 Sobre los diferentes atentados imputados a Osama bin Laden, Comisión Nacional de Investigación, Informe..., cit., pp. 80 y ss; Clarke, R., Contra todos los enemigos, Madrid, 2004, pp. 173 y 277.

14 Al respecto, Clarke, R., Contra..., cit., p. 231.

15 Clinton, B., Mi vida, Barcelona, 2004, p. 927.

16 Clarke, R., Contra..., cit., pp. 230 y 231. 
que estoy diciendo?". ${ }^{17} \mathrm{El}$ objetivo del ataque era eliminar a bin Laden y a sus lugartenientes. ${ }^{18}$

En este contexto, como escribe Albright, "no podíamos cruzarnos de brazos y esperar hasta que los terroristas volvieran al ataque [y] el presidente Clinton dio luz verde a una misión de represalia... Pretendíamos atacar tres bases terroristas cerca de Jost, a unos 145 kilómetros al sur de Kabul". ${ }^{19}$ Por su parte, Clinton escribe que se pasó dos días "planeando los ataques aéreos contra al-Qaeda [en Afganistán y en Sudán]. El momento del ataque en los campamentos tenía que coincidir con la reunión que, según los servicios secretos, mantendrían bin Laden y sus lugartenientes". ${ }^{20}$ Esta operación, que recibió el nombre de Alcance Infinito ${ }^{21}$ se inició a las once de la mañana del 20 de agosto y fueron lanzados setenta y nueve misiles de crucero Tomahawk desde buques de Estados Unidos de América destacados en el Mar Rojo y el Mar Arábigo, que alcanzaron sus blancos en Afganistán y Shifa (Sudán) un par de horas después. Como escribe Clinton, "a las 3 de la mañana di la orden definitiva para proceder. La mayoría de los misiles dio en el blanco, pero bin Laden no se encontraba en el campamento donde la CIA pensaba que estaría, cuando los misiles impactaron". ${ }^{22}$

Dos días después del ataque, el fundador y líder de los talibanes, Muhammad Omar Akhnud, se puso en contacto con Michael Malinowski, antiguo miembro del Departamento de Estado en Asuntos del Sur de Asia, para pedirle que las tropas estadounidenses se retiraran de Arabia Saudí. Por su parte, Malinowski solicitó la entrega de Osama bin Laden. ${ }^{23}$ Tras varias conversaciones, los líderes talibanes se negaron a entregar a Osama bin Laden a las autoridades estadounidenses, pues en caso de hacerlo violarían la tradición de no maltratar al beneficiario de su hospitalidad. Ante esta negativa, las autoridades estadounidenses les dijeron "Bin Laden ha matado a estadounidenses y planea volver a matar.

7 Citado en Clarke, R., Contra..., cit., pp. 231 y 232.

18 Comisión Nacional de Investigación, Informe..., cit., p. 105.

19 Albright, M., Memorias, Barcelona, 2004, p. 437.

20 Clinton, B., Mi vida, cit., pp. 932 y 933.

21 Sobre esta operación y su segunda parte, Operación Resolución Infinita, Comisión Nacional de Investigación, Informe..., cit., pp. 127-131.

22 Clinton, B., Mi vida, cit., p. 927.

23 Con anterioridad, en abril de 1998, el embajador de los Estados Unidos en las Naciones Unidas, Bill Richardson, visitó Kabul y "pidió a los talibanes que expulsaran a bin Laden. Le respondieron que ignoraban dónde estaba" (Comisión Nacional de Investigación, Informe..., cit., p. 99). 
Se ha convertido en nuestro enemigo. $\mathrm{Y}$ eso convierte en enemigos a quienes le apoyen" y, seguidamente, la administración Clinton comunicó al régimen talibán que "si bin Laden o cualquier seguidor de su organización ataca a Estados Unidos de América o intereses estadounidenses, consideraremos que ustedes son directamente responsables". ${ }^{24} \mathrm{Y}$, así, el régimen de Kabul unió su destino al de Osama bin Laden. Como recuerda Albright, con motivo de su viaje a Pakistán, dijo en público "con precisión y sin diplomacia: estamos contra los talibanes" 25 pues, como indica la Comisión Nacional de Investigación, "la secretaria Albright no ocultaba que consideraba a los talibanes 'despreciables"”. ${ }^{26}$

Escribe Albright que "al día siguiente de nuestros ataques de represalia con misiles, en agosto de 1998, la Casa Blanca convocó una reunión para estudiar futuras operaciones militares. Nuestro blanco principal no había sido alcanzado: la toma de una decisión era cada vez más ardua. En las semanas siguientes el presidente autorizó específicamente el uso de la fuerza para matar o capturar a Bin Laden y a sus asesores más conocidos". ${ }^{27}$ En concreto, el presidente Clinton señala que:

Firmé el primero de una serie de decretos... El decreto presidencial 13099 imponía sanciones económicas contra bin Laden y al Qaeda. Más tarde esas sanciones también se hicieron extensivas a los talibanes... También pedí que se desarrollaran diversas opciones para enviar unidades de comandos a Afganistán [pero] me di cuenta de que los mandos militares no querían hacerlo... También firmé diversos Memorándums de Notificación con los que permitía a la CIA al uso de la fuerza letal para apresar a bin Laden. ${ }^{28}$

24 Albright, M., Memorias, cit., pp. 443 y 444. En este contexto, Michael Sheedan coordinador de antiterrorismo, "insistió en que se emplearan todas las armas y medidas disponibles contra los talibanes” (citado en Comisión Nacional de Investigación, Informe..., cit., p. 115).

25 Albright, M., Memorias, cit., p. 436.

26 Comisión Nacional de Investigación, Informe..., cit., p. 99.

27 Albright, M., Memorias, cit., p. 448. Sobre los preparativos de las diferentes operaciones para acabar con Osama bin Laden, Clarke, R., Contra..., cit., pp. 248 y ss. Asimismo, sobre los planes de captura desarrollados por la CIA, Comisión Nacional de Investigación, Informe..., cit., pp. 99-103.

28 Clinton, B., Mi vida, cit., pp. 933 y 934. A este respecto, Clarke recuerda que con anterioridad le habían propuesto al presidente Clinton la "rendición extraordinaria" (operación para aprehender a terroristas en el extranjero sin que el gobierno hiciese ningún tipo de reconocimiento público) del único terrorista que faltaba por capturar relacionado con los atentados contra el World Trade Center en 1993. En la reunión el vicepresidente Al Gore dijo: “es una decisión fácil. Por supuesto que es una violación del derecho internacional; por eso tiene que ser una operación 
Empero, además de estas medidas, el presidente Clinton ordenó la elaboración de un plan global para acabar con al Qaeda. El plan político-militar, preparado por Clarke y su equipo, fue bautizado con el nombre Delenda est y calificado top secret. ${ }^{29} \mathrm{El}$ plan "proponía medidas diplomáticas para negar el refugio a bin Laden; operaciones secretas para desarticular actividades terroristas, pero por encima de todo capturar a bin Laden...; diversas medidas para cortar las reservas financieras de bin Laden; y preparativos varios para operaciones militares de seguimiento. El componente militar del plan de Clarke era el elemento formulado con mayor detalle. Describía una campaña de ataques permanentes contra las bases de bin Laden en Afganistán u otros territorios". ${ }^{30}$

En 1999 las discusiones de la administración Clinton sobre Afganistán se polarizaron en dos alternativas: llevar a cabo un esfuerzo diplomático para poner fin a la guerra civil afgana e instalar un gobierno de unidad nacional o emitir una declaración afirmando que los talibanes eran un grupo terrorista, para posteriormente enviar ayuda en secreto a su principal enemigo, la Alianza del Norte. En julio de ese año, el presidente Clinton emitió una orden ejecutiva declarando de hecho al régimen talibán como un Estado protector de terroristas y autorizó una operación secreta bajo unas condiciones muy definidas que, de tener éxito, hubiera supuesto la muerte de bin Laden. ${ }^{31}$

Según Albright, "nunca hubo dudas de que en cuanto creyéramos tener una buena ocasión para capturar a bin Laden, iríamos por él" ${ }^{32} \mathrm{Y}$ la ocasión no se presentó bajo el mandato de Clinton, ${ }^{33}$ pero sí durante el gobierno de Bush. Los atentados del 11 de septiembre se presentaron como el pretexto idóneo para actuar en Afganistán y, de esta forma, lle-

encubierta. Ese tipo es un terrorista. Id y traedlo de los huevos" (citado en Clarke, R., Contra..., cit., p. 184).

29 Sobre el plan Delenda est, en Clarke, R., Contra ..., cit., pp. 245 y ss.

30 Comisión Nacional de Investigación, Informe..., cit., pp. 110 y 111.

$31 \mathrm{Al}$ respecto, Comisión Nacional de Investigación, Informe..., cit., pp. 116 y 137.

32 Albright, M., Memorias..., cit., p. 449. Escribe Clarke que "la idea de bombardear toda la infraestructura de al Qaeda nunca se descartó. Lo cierto es que la Junta de Jefes de Estado Mayor recibió instrucciones de preparar planes para bombardear las instalaciones no sólo con misiles de crucero, sino también mediante ataques estratégicos de los bombarderos B-1, B-2 y B-52" (Clarke, R., Contra..., cit., p. 252).

33 "Los responsables políticos de la administración Clinton, incluyendo al presidente y a su asesor de seguridad nacional, nos dijeron que las intenciones del presidente respecto a las operaciones secretas contra bin Laden eran muy claras: lo quería muerto" (Comisión Nacional de Investigación, Informe..., cit., p. 125. Sobre las operaciones secretas, pp. 118-127). 
var a cabo la acción militar tan deseada desde la administración Clinton. Esta afirmación es confirmada por la propia Albright cuando escribe: "una cuestión que se ha planteado es por qué no invadimos sin más Afganistán, derrocamos a los talibanes y dispersamos a al Qaeda en su propio terreno... Habría habido razones para justificar la acción militar pero, sin el tremendo impacto del 11 de septiembre, la invasión de Afganistán no la habrían tolerado la mayoría de los ciudadanos. Y habría sido condenada por las comunidades árabes e islámicas del mundo entero". ${ }^{34}$

Escribe Clarke que "Clinton dejó el poder con bin Laden vivo, pero tras autorizar acciones para eliminarle y reforzar los ataques sobre al Qaeda", y no dudó de hablar "del tema con el presidente electo, Bush, [pero] lo cierto es que, en enero del 2001, la nueva administración pensó que la recomendación de Clinton de que la eliminación de al Qaeda fuera una de las máximas prioridades era extraña, como tantas otras acciones de la administración Clinton, desde su perspectiva" ${ }^{35}$ Asimismo, según Clarke (ahora bajo la administración Bush), en su primera reunión con los vicesecretarios para asuntos de seguridad nacional, Steve Hadley, y de defensa, Paul Wolfowitz, les advirtió de la necesidad de seguir presionando a los talibanes y Al Qaeda, en tanto que representaban una seria amenaza para los Estados Unidos de América. No obstante, sobre esta cuestión no se adoptaron medidas concretas ${ }^{36}$ y el tiempo fue pasando hasta el 11 de septiembre.

\section{UNA FECHA QUE VIVIRÁ EN LA INFAMIA: MARTES, 11 DE SEPTIEMBRE DEL 2001}

Escribe Reverte que "hay días o instantes de tu vida, que guardas en tu memoria, e incluso en tus sentidos, como si no se alejasen en el tiempo, como si se hubieran detenido en el espacio y habitasen siempre junto a ti. El primer beso en los labios de tu novia, aquel poema que abrió una herida de luz en tu alma, el nacimiento de un hijo, la muerte de tus pa-

34 Albright, M., Memorias..., cit., p. 450.

35 Clarke, R., Contra..., cit., pp. 280 y 281. Sobre la conversación Clinton-Bush, Comisión Nacional de Investigación, Informe..., cit., pp. 205 y 206.

36 El presidente Bush envió varios emisarios para presionar a los talibanes y "repitieron, una vez más, la advertencia de que los talibanes serían considerados responsables de cualquier atentado que al Qaeda perpetrara contra los intereses de Estados Unidos" (Comisión Nacional de Investigación, Informe..., cit., p. 214). 
dres o ese momento"37 en que se vivieron los atentados terroristas perpetrados en Nueva York y Washington el día 11 de septiembre del 2001.38 El llamado "martes negro" fue uno de los días más largos, uno de esos días que marcan una era y pasan a ocupar un lugar en la historia. Es el prototipo de día que todas las personas recuerdan lo que estaban haciendo cuando se produjo el atentado que conmovió al mundo. ${ }^{39} \mathrm{Un}$ atentado que, en palabras de Vargas Llosa, evidencia que "el siglo XXI será el de la confrontación entre el terrorismo de los movimientos fanáticos (nacionalistas o religiosos) y las sociedades libres". ${ }^{40}$ En fin, una fecha que, como dijera Franklin Delano Roosevelt ${ }^{41}$ con motivo del ataque sorpresa japonés a la base naval de Pearl Harbor, vivirá en la infamia.

El vuelo 11-AA de la compañía American Airlines, un Boeing 767-300 con 81 pasajeros y 11 tripulantes a bordo, despega del aeropuerto Logan de Boston a las 7:59 horas del martes 11 de septiembre del 2001 (13:59 horas en España) con destino a Los Ángeles. A las 8:20 horas el aparato asciende hasta su altitud de crucero y, simultáneamente, se desconecta el dispositivo que permite su localización. El capitán Jim Ogonowski, antes de ser asesinado, consigue dejar abiertos los micrófonos de forma intermitente y, de esta forma, los controladores de vuelo consiguen oír las siguientes palabras: "no hagáis nada estúpido, no resultaréis heridos". Poco después, la azafata Betty Ong consigue comunicar al centro de operaciones de American Airlines que el avión ha sido secuestrado por cinco personas, además informa de los números de los asientos de los secuestradores. El Boeing 767 de la American Airlines entra en el Estado de Nueva York a las 8:29 horas.

A las 7:59 horas despega el vuelo 77-AA de la American Airlines, un Boeing 757-200 con 58 pasajeros y seis tripulantes, del aeropuerto de Dulles de Washington con destino Los Ángeles. A las 8:41 horas el vuelo alcanza su velocidad de crucero y a las 9:00 horas, cuando sobrevuela

7 Reverte, J., Corazón de Ulises, Barcelona, 2004, p. 15.

38 Al respecto, Comisión Nacional de Investigación, Informe..., cit., pp. 17-29.

39 "Lo ocurrido el 11-S en Nueva York y Washington fue una barbarie inesperada, humillante y absolutamente condenable. Si a ese hecho se añaden las reacciones del gobierno de EUA, de las democracias occidentales, de las Naciones Unidas, y también de los países árabes, y, si se junta la guerra y destrucción de Afganistán, bien puede decirse que es un trágico símbolo de nuestro mundo" (Sobrino, J., "Redención del terrorismo", Política Exterior, 2002, núm. 85, p. 128).

40 Vargas Llosa, M., "La lucha final", El País, 16 de septiembre del 2001.

41 Roosevelt, F., "Washington, 8 de diciembre de 1941", Los discursos del poder, Barcelona, 2003, p. 475. 
Ohio, da media vuelta y la torre de control deja de recibir la comunicación del traspondedor (mecanismo que indica el número de vuelo, la altitud y el rumbo). Sin embargo, atendiendo a que el espacio aéreo de Washington y sus alrededores está clasificado como de alta seguridad y ninguna nave puede sobrevolarlo sin autorización, el avión es detectado y calificado como "objetivo primario" (no identificado) con dirección a la Casa Blanca. Se produce la alarma, pero seguidamente el avión vira 270 grados y enfila hacia el Pentágono desde el suroeste.

A las 8:01 horas el vuelo 93-UA de la compañía United Airlines, un Boeing 757-200 con 38 pasajeros y siete tripulantes, despega del aeropuerto Newark de New Jersey con destino San Francisco. Pocos minutos después del despegue, mientras el aparato modifica su rumbo sobre Pensilvania, varios pasajeros telefonean a través de sus móviles a familiares e informan que el avión ha sido secuestrado. El nuevo rumbo es dirección Washington.

El vuelo 175-UA de United Airlines, un Boeing 767-300 con 56 pasajeros y nueve tripulantes, con destino Los Ángeles despega a las 8:15 horas del aeropuerto de Logan de Boston. Media hora después, el aparato vira a la izquierda y abandona el plan de vuelo y la ruta oficial. Doce minutos más tarde vuelve a girar y pone rumbo hacia la ciudad de Nueva York.

A las 8:48 horas el Boeing 767 (vuelo 11-AA) de la American Airlines impacta contra los pisos superiores de la Torre Gemela Norte del World Trade Center de Manhattan. Dieciocho minutos más tarde, el Boeing 767 (vuelo 175-UA) de la United Airlines impacta en la Torre Gemela Sur. A las 9:43 horas el Boeing 757 (vuelo 77-AA) de la American Airlines se estrella contra el ala suroeste del edificio del Pentágono. A las 10:05 la Torre Sur del World Trade Center se hunde. Cinco minutos después, a las 10:10 horas, el Boeing 757 (vuelo 93-UA) de la United Airlines se estrella en las proximidades de Shanksville, un pueblo de 250 habitantes, en el Estado de Pensilvania. A las 10:28 horas se derrumba la Torre Norte. Cien minutos de explosiones, pánico e incertidumbre. En apenas una hora y cuarenta minutos el nuevo milenio asiste a "la globalización del terror":42 "desde el 11-S vivimos en una atmósfera mundial

42 González, F., "La globalización del terror", El País, 15 de septiembre del 2001. Sobre esta cuestión, Rodríguez Zapatero, J., "España y Europa ante la crisis”, Política Exterior, 2001, núm. 84, pp. 27 y ss. 
donde los riesgos, amenazas e incertidumbres se han vuelto más perceptibles y condicionantes. A pesar de su lejanía geopolítica de las zonas calientes de la guerra antiterrorista (Oriente Próximo, sureste asiático, África...), el carácter global de la marea terror-contraterror incide de forma indirecta y con efectos retardados que conviene no minimizar". ${ }^{43}$

Así se consumaba el ataque perpetrado por terroristas contra Estados Unidos de América ${ }^{44}$ en propio suelo estadounidense. ${ }^{45}$ Una acción terrorista que solamente parecía tener cabida en la imaginación del prolífico escritor Tom Clancy, ${ }^{46}$ cuando hizo sucumbir el Capitolio de Washington ante el impacto de un Boeing 747 en manos de un piloto suicida al servicio de los intereses de un grupo de extremistas islámicos. Lo anticipado en esta novela, la vulnerabilidad de la única superpotencia planetaria, ha dejado de ser una mera ficción. La soñada seguridad total bajo un escudo nuclear ha sido rota y puesta en cuestión por el terrorismo. ${ }^{47} \mathrm{La}$ sociedad internacional en general y la estadounidense en particular descubren atónitas e impotentes cómo un grupo de terroristas golpean el corazón del "gendarme" mundial, tan acostumbrado a librar sus guerras lejos de casa.

43 Medina, G., "América latina en la marea del 11 de septiembre", Politica Exterior, 2002, núm. 85 , p. 156 .

44 Sobre los preparativos y desarrollo de los atentados, Comisión Nacional de Investigación, Informe..., cit., pp. 230 y ss.

45 Otros ataques terroristas contra intereses de los Estados Unidos de América han sido: Abril de 1983: un coche bomba explota contra la embajada de los Estados Unidos de América en Beirut/Libano (mueren 79 personas). Octubre de 1983: un camión bomba impacta contra el Cuartel General de los Marines en Beirut/Libano (mueren 239 personas). Septiembre de 1986: un grupo propalestino secuestra un Boeing 747 en Karachi/Pakistán (mueren 17 personas). Diciembre de 1988: un Boeing 747 de la Pan Am estalla cuando sobrevolaba Lockerbie/Reino Unido (mueren 270 personas). Febrero de 1993: un coche bomba explota bajo las Torres Gemelas en Nueva York/Estados Unidos de América (mueren 6 personas). Noviembre de 1995: un coche bomba explota en Riad/Arabia Saudí (mueren 7 personas, 5 son estadounidenses). Junio de 1996: un camión bomba explota en una base aérea de Dhahran/Arabia Saudí (mueren 19 soldados estadounidenses). Agosto de 1998: dos coches bombas explotan ante las embajadas de Estados Unidos de América en Nairobi/Kenya y Dar es Salaam/Tanzania (mueren 230 personas). Octubre del 2000: una lancha bomba colisiona contra el destructor USS Cole en Aden/Yemen (mueren 17 personas).

46 Clancy, T., Órdenes ejecutivas, Barcelona, 1998, t. I.

47 "Las tendencias sugieren que el mundo se está volviendo un lugar turbio y más peligroso... Los Estados delincuentes pueden usar de modo creciente estrategias asimétricas para retar el poder militar de Estados Unidos de un modo indirecto pero potencialmente eficaz... Estas estrategias abarcan ataques a objetivos blandos como población civil estadounidense e instalaciones no militares... El terrorismo se está incorporando progresivamente hacia EE.UU y los símbolos de su poder más que hacia intereses comerciales y el mundo occidental en general" (Instituto para Estudios Estrategicos Nacionales de EEUU, Strategic assessment, 1999). 
La conmoción mundial es enorme después de ver las escalofriantes imágenes de la caída de las Torres Gemelas. Conmoción que deja rápidamente paso a un sentimiento de indignación y a numerosas muestras de apoyo y condena por parte de las autoridades de diferentes Estados y organizaciones internacionales. ${ }^{48}$ Los atentados suicidas de Nueva York, Washington y el frustrado por los propios pasajeros en Pensilvania, muestran la vulnerabilidad de los Estados ante este tipo de acciones. Desde una perspectiva moral y política "el terrorismo como método es igual en todas partes y no cabe hacer distinciones entre unos y otros grupos. No obstante, los atentados en Nueva York y Washington confirman un terrorismo de última hornada, con una creciente espiral de destrucción. Por los daños causados, esos ataques han avisado sobre la realidad de un terrorismo catastrófico de masas, que se puede denominar hiperterrorismo". 49

La pesadilla del martes negro pone sobre el tapete una realidad: la negligencia exhibida por la sociedad internacional a la hora de combatir el problema terrorista. Empero, si puede servir de consuelo, desde ese mismo martes se está tomando conciencia real de que "a nivel internacional" el terrorismo no es un problema que afecta únicamente a determinados países, sino que se trata de un problema global que requiere una solución también global: "los atentados del 11 de septiembre de este año en Nueva York y Washington han situado al terrorismo internacional entre las amenazas globales que desbordan la capacidad de respuesta del Estado individualmente considerado... lo que requiere profundizar en la cooperación internacional a nivel mundial, como ha hecho la Resolución 1373 del Consejo de Seguridad". ${ }^{50}$ En fin, un día después de la operación Alcance Infinito, ordenada por el ex presidente Clinton contra Al Qaeda, el entonces consejero de Seguridad Nacional estadounidense, Sandy Berger, declaró que estaba "absolutamente seguro [de] que, de no haberlo hecho, habríamos sido víctimas de otros ataques terroristas a no tardar

48 Las declaraciones de apoyo y condena aparecen recogidas en la publicación especial de actualidad EE.UU., en llamas, contraataca. El atentado conmueve al mundo: víctimas, autores, responsables, reacciones, Barcelona, s. f., pp. 41 y ss.

49 Bardaji, R y Cosido, I., "El fin de la disuasión”, Política Exterior, 2001, núm. 84, p. 155.

50 González Campos, J.; Sánchez Rodríguez, L. y Andrés Sáenz de Santa María, M., Curso de derecho internacional público, Madrid, 2002, pp. 27 y 28. 
mucho". ${ }^{51}$ Empero, la realidad del día 11 de septiembre del 2001 demostró su error.

\section{LA REACCIÓN DEL CONSEJO DE SEGURIDAD. LAS RESOLUCIONES 1368 (2001) Y 1373 (2001)}

Los atentados terroristas perpetrados en Nueva York y Washington el día 11 de septiembre del 2001 marca un punto de inflexión tanto en la lucha internacional contra el terrorismo como en la figura de la legítima defensa. En la Resolución 1368 (2001) ${ }^{52}$ de 12 de septiembre - adoptada unánimemente-, el Consejo de Seguridad se manifestó decidido a tomar todas las medidas necesarias para responder a los ataques terroristas ${ }^{53}$ y combatirlos en todas sus formas de conformidad con las funciones atribuidas por la Carta de las Naciones Unidas. Escribe Fernández de Casadevante Romaní que:

Las medidas adoptadas para hacer frente a los atentados terroristas del 11 de septiembre de 2001 contra los Estados Unidos de América pudieron constituir un punto de inflexión respecto a la conducta adoptada por la OTAN en Kosovo. Entre ellas, la rápida y unánime reacción del Consejo de Seguridad calificando esos y todos los actos de terrorismo internacional "como una amenaza a la paz y a la seguridad internacionales", declarándose dispuesto a adoptar todas las medidas necesarias para responder a los ataques terroristas del 11 de septiembre y para combatir el terrorismo bajo cualquiera de sus formas, conforme a sus responsabilidades en virtud de la Carta de las Naciones Unidas [Consejo de Seguridad, Resolución 1368 (2001) de 12 de septiembre de 2001, párrafos 1 y 5]. Pero, al mismo tiempo, la evolución de los acontecimientos volvió a poner de manifiesto la debilidad de esta Organización Internacional cuando el Consejo de Seguridad no asume el papel institucional que le otorga la carta y deja la respuesta en manos del Estado lesionado, quien actúa sin ningún tipo de control internacional..$^{54}$

51 Citado en Remiro Brotóns, A., "El orden internacional tras los atentados del 11 de septiembre de 2001", Revista Española de Derecho Internacional, 2001, núm. 1 y 2, p. 142.

52 Stahn, C., "Security Council Resolutions 1368 (2001) and 1373 (2001). What they say and what they do not say", European Journal of International Law (http://www.ejil.org/forum-WTC/ny).

53 Sobre esta cuestión en general, Bourgues, C., "Le terrorisme international", Droit international penal, París, 2000, pp. 457 y ss.; Guillaume, G., "Terrorisme et droit international”, RCADI, 1989, vol. 215, pp. 304 y ss.

54 Fernández de Casadevante Romaní, C., Derecho internacional público, Madrid, 2003, p. 36. 
La reacción del Consejo de Seguridad ${ }^{55}$ ante los atentados perpetrados en Nueva York y Washington no se hizo esperar. Un día después de los atentados, el 12 de septiembre, el Consejo de Seguridad adoptó, por unanimidad, la Resolución $1368(2001)^{56}$ en la que se manifestó decidido a tomar todas las medidas necesarias para responder a los ataques terroristas y combatirlos en todas sus formas, de conformidad con las funciones atribuidas por la Carta de las Naciones Unidas. En esta resolución, entre otras cuestiones, el Consejo de Seguridad dispone los siguientes extremos: 1) La consideración de dichos ataques, al igual que cualquier acto de terrorismo internacional, como constitutivos de una amenaza para la paz y la seguridad internacionales; 2) La necesidad por parte de todos los Estados de colaborar con urgencia para someter a la justicia a los autores, organizadores y patrocinadores de los ataques. Asimismo, los cómplices de éstos y los responsables de darles apoyo o asilo tendrán que rendir cuenta de sus hechos; 3) La exhortación a la sociedad internacional para que redoble sus esfuerzos por prevenir y reprimir los actos de terrorismo en particular, cooperando y cumpliendo plenamente los convenios internacionales contra el terrorismo y las resoluciones del Consejo de Seguridad, especialmente la 1269 (1999), de 19 de octubre.

A partir de las premisas dispuestas en la Resolución 1368 (2001) y en el marco del capítulo VII de la carta, el Consejo de Seguridad adopta la Resolución 1373 (2001), de 28 de septiembre. En esta nueva resolución, jurídicamente vinculante, se declara que los actos, métodos y prácticas terroristas son contrarios a los propósitos y principios de las Naciones Unidas y que financiar intencionalmente actos de terrorismo, planificarlos e incitar a su comisión también es contrario a dichos propósitos y principios, articulándose así la futura lucha contra el terrorismo internacional. Se trata, pues, de una resolución susceptible de ser catalogada como histórica ya que marca en el plano internacional un antes y un después en el intento de erradicar el fenómeno terrorista.

En conformidad con esta resolución, todos los Estados deben prevenir y reprimir la financiación de los actos de terrorismo; tipificar como delito la provisión o recaudación intencionales, por cualesquiera medios,

55 Al respecto, Alcaide Fernández, J., "La guerra contra el terrorismo: ¿Una opa hostil al derecho de la comunidad internacional?", Revista Española de Derecho Internacional, 2001, núms. 1 y 2, pp. 289 y ss.

56 Stahn, C., "Security Council Resolutions 1368 (2001) and 1373 (2001). What they say and what they do not say", European Journal of International Law (http://www.ejil.org/forum-WTC/ny). 
directa o indirectamente, de fondos por sus nacionales o en sus territorios con intención de que dichos fondos se utilicen, o con conocimiento de que dichos fondos se utilizarán, para perpetrar actos de terrorismo; congelar sin dilación los fondos y demás activos financieros o recursos económicos de las personas que cometan o intenten cometer actos de terrorismo o participen en ellos o faciliten su comisión; de las entidades de propiedad o bajo el control, directos o indirectos, de esas personas, y de las personas y entidades que actúen en nombre de esas personas y entidades o bajo sus órdenes, inclusive los fondos obtenidos o derivados de los bienes de propiedad o bajo el control, directos o indirectos, de esas personas y de las personas y entidades asociadas con ellos; prohibir a sus nacionales o a todas las personas y entidades en sus territorios que pongan cualesquiera fondos, recursos financieros o económicos o servicios financieros o servicios conexos de otra índole, directa o indirectamente, a disposición de las personas que cometan o intenten cometer actos de terrorismo o faciliten su comisión o participen en ella, de las entidades de propiedad o bajo el control, directos o indirectos, de esas personas y de las personas y entidades que actúen en nombre de esas personas o bajo sus órdenes.

Asimismo, todos los Estados deben: abstenerse de proporcionar todo tipo de apoyo, activo o pasivo, a las entidades o personas que participen en la comisión de actos de terrorismo, inclusive reprimiendo el reclutamiento de miembros de grupos terroristas y eliminando el abastecimiento de armas a los terroristas; adoptar las medidas necesarias para prevenir la comisión de actos de terrorismo, inclusive mediante la provisión de alerta temprana a otros Estados mediante el intercambio de información; denegar refugio a quienes financian, planifican o cometen actos de terrorismo, o prestan apoyo a esos actos, o proporcionan refugios; impedir que quienes financian, planifican, facilitan o cometen actos de terrorismo utilicen sus territorios respectivos para esos fines, en contra de otros Estados o de sus ciudadanos; asegurar el enjuiciamiento de toda persona que participe en la financiación, planificación, preparación o comisión de actos de terrorismo o preste apoyo a esos actos, y aseguren que, además de cualesquiera otras medidas de represión de esos actos que se adopten, dichos actos de terrorismo queden tipificados como delitos graves en las leyes y otros instrumentos legislativos internos y que el castigo que se imponga corresponda a la gravedad de esos actos de terrorismo; proporcionar recíprocamente el máximo nivel de asistencia en lo que se refiere 
a las investigaciones o los procedimientos penales relacionados con la financiación de los actos de terrorismo o el apoyo prestado a éstos, inclusive por lo que respecta a la asistencia para la obtención de las pruebas que posean y que sean necesarias en esos procedimientos; impedir la circulación de terroristas o de grupos terroristas mediante controles eficaces en frontera y controles de la emisión de documentos de identidad y de viaje, y mediante la adopción de medidas para evitar la falsificación, la alteración ilegal y la utilización fraudulenta de documentos de identidad y de viaje.

Los Estados tienen que encontrar medios para intensificar y agilizar el intercambio de información operacional, especialmente en relación con las actividades o movimientos de terroristas individuales o de redes de terroristas; los documentos de viaje alterados ilegalmente o falsificados; el tráfico de armas, explosivos o materiales peligrosos; la utilización de tecnologías de las comunicaciones por grupos terroristas y la amenaza representada por la posesión de armas de destrucción en masa por parte de grupos terroristas; intercambiar información de conformidad con el derecho internacional y la legislación interna y cooperar en las esferas administrativas y judiciales para impedir la comisión de actos de terrorismo; cooperar, en particular mediante acuerdos y convenios bilaterales y multilaterales, para impedir y reprimir los ataques terroristas, y adoptar medidas contra quienes cometan esos actos; adherirse tan pronto como sea posible a los convenios y protocolos internacionales pertinentes relativos al terrorismo, inclusive el Convenio Internacional para la Represión de la Financiación del Terrorismo, de 9 de diciembre de 1999; fomentar la cooperación y aplicar plenamente los convenios y protocolos internacionales pertinentes relativos al terrorismo, así como las resoluciones del Consejo de Seguridad 1269 (1999) y 1368 (2001); adoptar las medidas apropiadas de conformidad con las disposiciones pertinentes de la legislación nacional y el derecho internacional, inclusive las normas internacionales en materia de derechos humanos, antes de conceder el estatuto de refugiado, con el propósito de asegurarse de que el solicitante de asilo no haya planificado o facilitado actos de terrorismo ni participado en su comisión; asegurar, de conformidad con el derecho internacional, que el estatuto de refugiado no sea utilizado de modo ilegítimo por los autores, organizadores o patrocinadores de los actos de terrorismo, y que no se reconozca la reivindicación de motivaciones políticas como causa de denegación de las solicitudes de extradición de presuntos terroristas. 
Por otra parte, el Consejo de Seguridad muestra su preocupación por la conexión que existe entre el terrorismo internacional y la delincuencia transnacional organizada, las drogas ilícitas, el blanqueo de dinero, el tráfico ilícito de armas y la circulación ilícita de materiales nucleares, químicos, biológicos y otros materiales letales, y a ese respecto pone de relieve la necesidad de promover la coordinación de las iniciativas nacionales, subregionales, regionales e internacionales, para reforzar la respuesta internacional a esta amenaza grave a la seguridad internacional.

Como puede advertirse, la Resolución 1373 (2001) no solamente viene referida a los atentados terroristas perpetrados en Nueva York, Washington y Pensilvania, sino que va mucho más allá en su determinación de poner contra las cuerdas al terrorismo internacional. ${ }^{57}$ Así pues, espe-

57 El 12 de noviembre, el Consejo de Seguridad adopta la Resolución 1377 (2001) en la que nuevamente insta a todos los Estados a intensificar sus esfuerzos por eliminar el flagelo del terrorismo internacional. El Consejo de Seguridad declara que los actos de terrorismo internacional constituyen una de las amenazas más graves para la paz y la seguridad internacionales en el siglo XXI y constituyen un desafío para todos los Estados y para toda la humanidad; Reafirma su condena inequívoca de todos los actos, métodos y prácticas del terrorismo, por ser criminales e injustificables, cualquiera que sea su motivación, en todas sus formas y manifestaciones, dondequiera se cometan y quienquiera los cometa; Destaca que los actos de terrorismo internacional son contrarios a los propósitos y principios de la Carta de las Naciones Unidas y que la financiación, la planificación y la preparación de actos de terrorismo internacional, así como todas las demás formas de apoyo a esos actos, son igualmente contrarios a los propósitos y principios de la Carta de las Naciones Unidas; Subraya que los actos de terrorismo ponen en peligro vidas inocentes y la dignidad y seguridad de los seres humanos en todas partes, amenazan el desarrollo social y económico de todos los Estados y menoscaban la estabilidad y la prosperidad mundiales; Afirma que, para combatir el flagelo del terrorismo internacional, es imprescindible aplicar un enfoque coherente y amplio, con la participación y la colaboración activas de todos los Estados Miembros de las Naciones Unidas y de conformidad con la Carta de las Naciones Unidas y con el derecho internacional; Destaca que los persistentes esfuerzos internacionales por promover la comprensión entre las civilizaciones y abordar los conflictos regionales y toda la gama de problemas de alcance mundial, entre ellos las cuestiones relativas al desarrollo, contribuirán a la cooperación y colaboración internacionales, que de por sí son necesarias para sostener la lucha más amplia posible contra el terrorismo internacional; Acoge con beneplácito el compromiso de luchar contra el flagelo del terrorismo internacional, expresado por los Estados en los debates de las sesiones plenarias de la Asamblea General celebradas del 1o. al 5 de octubre de 2001, entre otras ocasiones, insta a todos los Estados a adherirse lo antes posible a los convenios y protocolos internacionales pertinentes relativos al terrorismo, y alienta a los Estados Miembros a avanzar en esta dirección; Insta a todos los Estados a que adopten medidas urgentes para aplicar plenamente la resolución 1373 (2001) y a que se ayuden mutuamente en esta tarea, y pone de relieve la obligación de los Estados de denegar asistencia financiera y todas las demás formas de apoyo y de refugio a los terroristas y a los que apoyan el terrorismo; Expresa su determinación de llevar adelante la aplicación de esa resolución en plena cooperación con todos los Miembros de las Naciones Unidas, y acoge con beneplácito los progresos realizados hasta el momento por el Comité contra el Terrorismo establecido en virtud del párrafo 6 de la resolución 1373 (2001) para verificar la aplicación de esa resolución; Reconoce que muchos Estados necesitarán asistencia para aplicar todas las medidas previstas en la resolución 1373 
cial importancia revisten los extremos relativos, por un lado, a que los Estados se abstengan de proveer cualquier tipo de apoyo, ya sea activo o pasivo, a organizaciones o personas implicadas en actos terroristas y, por otro, la demanda a los Estados de que no concedan refugio a los terroristas ni permitan la utilización de su territorio a fines de actos terroristas. En definitiva, con esta resolución se inicia la cruzada internacional contra el terrorismo y, por ello, el Consejo de Seguridad expresa su determinación de adoptar todas las medidas necesarias para asegurar su aplicación plena de conformidad con las funciones que se le asignan en la carta.

Empero, desde el punto de vista del denominado derecho a la legítima defensa, ${ }^{58}$ la Resolución 1368 (2001) contiene dos extremos esenciales, a saber: el reconocimiento del derecho inmanente a la legitima defensa individual o colectiva de conformidad con la carta (adviértase que no reconoce en concreto este derecho a los Estados Unidos de América), por un lado, y la utilización del término ataques - y no el de "atentado"- respecto de las acciones terroristas perpetradas el 11 de septiembre, por otro. Posteriormente, la Resolución 1373 (2001) reafirma el derecho inmanente de legítima defensa individual o colectiva reconocido en la Carta de las Naciones Unidas. Ahora bien, debe observarse que "en el caso de las acciones armadas contra el régimen de los talibanes como consecuencia de los atentados terroristas del 11 de septiembre de 2001, el Consejo de Seguridad ni siquiera ha procedido a autorizar el uso de la fuerza, limitándose a incluir en el preámbulo de las Resoluciones 1368 y 1373 (2001) un ambiguo reconocimiento del derecho inmanente de legítima defensa individual o colectiva de conformidad con la Carta de las NU". ${ }^{59}$

\section{LA ADMINISTRACIÓN BUSH Y LA OPERACIÓN LIBERTAD DURADERA}

Poco después de los atentados terroristas del 11 de septiembre, ${ }^{60}$ Clarke, informó al vicepresidente Cheney y a la consejera para asuntos de se-

(2001), e invita a los Estados a informar al Comité contra el Terrorismo de los ámbitos en los que necesitarán apoyo.

$58 \mathrm{Al}$ respecto, Ortega Carcelen, M., La legítima defensa del territorio del Estado, Madrid, 1991.

59 González Campos, J; Sánchez Rodríguez, L y Andrés Sáenz de Santa María, M., Curso..., cit., p. 914.

$60 \mathrm{Al}$ respecto, Comisión Nacional de Investigación, Informe..., cit., pp. 148 y ss. 
guridad nacional, Condolezza Rice, que se trataba de "un ataque de Al Qaeda" y, al respecto, el director de la CIA, George Tenet, "no dejó ninguna duda de que era Al Qaeda quien había cometido estas atrocidades". ${ }^{61}$ Seguidamente, en el gabinete de crisis, Rich Armitage, número dos del departamento de Estado (Colin Powell se encontraba en el Perú), dijo a los asistentes: "les dijimos claramente a los talibanes que si esto ocurría iríamos por ellos. Ahora no hay que diferenciar entre los talibanes y al Qaeda. La cosa va con los dos".

La mañana del día 12, la CIA declaró explícitamente que Al Qaeda era culpable de los atentados, sin embargo, para Paul Wolfowitz, vicesecretario de Defensa, se trataba de una operación muy compleja para ser realizada tan sólo por un grupo terrorista, sin que un Estado les hubiera ayudado. Ese Estado muy bien podría ser Iraq. Ese mismo día, en una reunión con el presidente Bush, y en presencia del coordinador del Consejo Nacional de Seguridad, ${ }^{62}$ el secretario de Defensa Rumsfeld observó que se debería bombardear Iraq y, seguidamente, el presidente señaló que lo que tenían que hacer con Iraq era cambiar el gobierno y no simplemente atacarlo con misiles. Ante la postura de Bush, el presidente de la Junta de Jefes de Estado Mayor, Hugh Shelton, advirtió que la preparación de tal operación llevaría meses, pues sólo podía conseguirse mediante una invasión que utilizara un contingente de fuerzas muy numeroso. Por consiguiente, a pesar de que no había prueba alguna que implicase a Iraq con los atentados, el presidente Bush ya tenía in mente concentrar sus esfuerzos bélicos contra el régimen iraquí como forma de demostrar el poder de Estados Unidos de América:

El presidente Bush ha dicho que el 11 de septiembre marcó un punto de inflexión en su idea de Iraq. También hubo un supuesto momento en que decidió acudir a Naciones Unidas y otro en que decidió no esperar más a ese organismo, pero en todo momento parecía inevitable que invadiéramos. Se representaba a Iraq como lo más peligroso para la seguridad nacional. Era una idea fija, un pensamiento rígido, un lugar común, una decisión tomada de antemano que ningún hecho ni acontecimiento podría desbaratar. ${ }^{63}$

61 Clarke, R., Contra..., cit., pp. 16 y 41.

62 Ibidem, pp. 51 y 52.

63 Ibidem, p. 328. 
En fin, este mismo día Wolfowitz declaró que la respuesta a los atentados "será una campaña militar, no una acción aislada... Es necesario eliminar a los Estados que apoyan al terrorismo". ${ }^{64}$

Como puede advertirse, la postura manifestada por la administración Bush responde a los planteamientos y objetivos perseguidos por los "neoconservadores" Rumsfeld y Wolfowitz, ${ }^{65}$ esto es, endurecer el unilateralismo estadounidense y ampliar la "guerra contra el terrorismo" más allá de Al Qaeda y el régimen talibán incluyendo tanto Iraq como todos los grupos terroristas islámicos. Y, así, en el mensaje dirigido por el presidente Bush a la nación desde el despacho oval afirmó que "no haremos distinciones entre los terroristas que han cometido los crímenes y quienes les han ayudado". Inmediatamente después de la emisión del discurso, el secretario Donald Rumsfeld hizo notar que el derecho internacional sólo permitía el uso de la fuerza para evitar futuros ataques y no como castigo, el presidente Bush le respondió "No. No me importa lo que diga el derecho internacional; alguien va a enterarse de lo que es bueno". ${ }^{66}$ Finalmente, el día 13 se alcanzó el consenso de "que la lucha contra Al Qaeda y los talibanes sería la primera etapa de una guerra más amplia contra el terrorismo" ${ }^{67} \mathrm{o}$, en otras palabras, tras la acción bélica en Afganistán (porque era el refugio del grupo Al Qaeda, responsable de los atentados), sería el turno de Iraq (que no tenía nada que ver con los atentados).

Una vez cometidos los atentados del 11 de septiembre y atribuida su autoría al grupo Al Qaeda, se les presentaba a los Estados Unidos de América la ocasión perfecta para capturar a Osama bin Laden. Sin embargo, la actuación llevada a cabo por la administración Bush parecía más bien encaminada a conseguir "un cambio de régimen que como una operación de búsqueda y destrucción de los terroristas"68 y, al respecto, no debe olvidarse que tal cuestión no era nueva, pues la misma ya se ha-

64 Citado en De Ruiter, R., El 11 de septiembre 2001. Mitos y mentiras, Frankfurt, 2004, p. 13.

65 Todorov, T., El nuevo desorden mundial, Barcelona, Península, 2003, pp. 19 y ss.

66 Ambas citas recogidas en Clarke, R., Contra..., cit., pp. 42 y 43. El 20 de septiembre del 2001, el presidente Bush en su discurso ante la sesión conjunta del congreso y Senado afirmó, respecto a la entrega de los terroristas de Al Qaeda, que "estas exigencias no están sujetas a negociación ni discusión. El Talibán debe actuar y actuar inmediatamente. Entregarán a los terroristas, o compartirán su destino" (http://www.whitehouse.gov /news 7releases/2001/09/200109 20-8.html).

67 Ibidem, p. 52.

68 Ibidem, p. 339. 
bía planteado bajo la administración Clinton. No obstante, antes de enviar las fuerzas armadas inmediatamente para capturar a Osama bin Laden y emprender las acciones militares, la administración Bush ofreció la posibilidad al régimen talibán de entregarlo y, de esta forma, evitar el conflicto armado. El gobierno de Kabul se negó a la entrega de Osama bin Laden.

El 7 de octubre, tras fracasar un nuevo llamamiento del presidente Bush a los talibanes para que entregaran a Osama bin Laden, los Estados Unidos de América iniciaron, bajo la denominación de operación Libertad Duradera, la campaña militar en Afganistán, ${ }^{69}$ pues Al Qaeda y el régimen talibán fueron definidos como un mismo objetivo estratégico. Mientras se bombardeaban desde el aire selectivamente los campamentos de Al Qaeda y las instalaciones militares de los talibanes, las operaciones terrestres, con el apoyo aéreo estadounidense, corrieron a cargo de la Alianza del Norte afgana, asesorada por un pequeño grupo de las fuerzas especiales estadounidenses. El 13 de noviembre las fuerzas de la alianza entraron en Kabul y el 25 de ese mismo mes entraron en acción los marines para tomar varios campamentos de $\mathrm{Al}$ Qaeda e instalaciones militares de los talibanes próximas a la ciudad de Kandahar. Sin embargo, no pudieron entrar en dicha ciudad hasta el 7 de diciembre y, obviamente, cuando lo hicieron no encontraron ni al mulláh Muhammad Omar Akhnud ni a Osama bin Laden, que habían huido a las montañas. En tres meses había sido derrocado el régimen talibán y, paradójicamente, cinco meses después del inicio de los combates, las tropas estadounidenses empezaron la Operación Anaconda destinada a "barrer" las montañas en busca del enemigo número uno de los Estados Unidos de América.

El presidente Bush dijo que Estados Unidos de América capturaría a Osama bin Laden "vivo o muerto", pero al día de hoy no ha sido capturado. Así las cosas, el Pentágono fue objeto de numerosas críticas hasta el extremo de que, poco antes de las navidades de ese año, el secretario Rumsfeld dijo públicamente "que en el futuro las fuerzas armadas de Estados Unidos de América harían el trabajo ellas mismas". ${ }^{70}$ Después de las acciones bélicas en Afganistán, los Estados Unidos de América no han conseguido eliminar Al Qaeda, pero si cambiar el régimen talibán y,

69 Mcinnes, C., "A different kind of war? September 11 and the United States' Afghan war", International Affairs, 2003, núm. 4, pp. 165 y ss.

70 Clarke, R., Contra..., cit., pp. 340 y 341, respectivamente. 
por consiguiente, la pregunta es ¿ha sido realmente un fracaso la acción militar en Afganistán? ¿cuál era el objetivo "real" perseguido por la administración Bush? ¿la captura de Osama bin Laden o el derrocamiento del régimen talibán?

La respuesta únicamente la conoce el presidente Bush, pero lo cierto es que: 1) La reacción de los Estados Unidos de América no fue rápida (26 días después de los atentados) y, además, se desconocía el paradero concreto de Osama bin Laden; 2) Las acciones armadas terrestres fueron llevadas a cabo por las fuerzas afganesas de la Alianza del Norte y los marines intervinieron casi dos meses después de iniciada la ofensiva; 3) En ningún momento se tomaron medidas para "bloquear" las fronteras con Pakistán e intentar impedir la huída; 4) La búsqueda de Osama bin Laden por las montañas se iniciaron cinco meses después de la ofensiva; y 5) Las fuerzas especiales estadounidenses fueron retiradas de Afganistán (con destino próximo en Iraq).

\section{EL MARCO JURÍDICO DE LA LEGÍTIMA DEFENSA, LOS ATENTADOS DEL 11 DE SEPTIEMBRE Y LA RESPUESTA ESTADOUNIDENSE}

Atendiendo a que en el preámbulo de la Resolución 1368 (2001) se recuerda el derecho a la legítima defensa y, posteriormente, este derecho es reafirmado en la Resolución 1373 (2001), el 8 de octubre los Estados Unidos de América y el Reino Unido ${ }^{71}$ informaron al Consejo de Seguridad de la operación Libertad Duradera bajo la cobertura del derecho inmanente de legítima defensa reconocido en el artículo 51 de la carta. Empero ¿se ajusta la respuesta estadounidense al marco jurídico que regula el ejercicio del derecho a la legítima defensa? ¿se ha desarrollado la intervención estadounidense conforme a las condiciones exigidas para actuar en el ámbito de la legítima defensa, tal como recuerda el Consejo de Seguridad en las resoluciones mencionadas?

\section{El derecho de legítima defensa y los atentados del 11 de septiembre}

El recurso a la fuerza está prohibido en las relaciones internacionales, pero no todo el uso de la fuerza es contrario al derecho internacional 
$\mathrm{y}$, de esta forma, cabe afirmar la existencia de excepciones a la referida prohibición; es decir, bajo determinadas condiciones el uso de la fuerza está permitido por la normativa internacional, tal es el caso de la legítima defensa. El artículo 51 de la Carta de las Naciones Unidas estipula que:

Ninguna disposición de esta Carta menoscabará el derecho inmanente de legítima defensa, individual o colectiva, en caso de ataque armado contra un Miembro de las Naciones Unidas, hasta tanto que el Consejo de Seguridad haya tomado las medidas necesarias para mantener la paz y la seguridad internacionales. Las medidas tomadas por los Miembros en ejercicio del derecho de legítima defensa serán comunicadas inmediatamente al Consejo de Seguridad, y no afectarán en manera alguna la autoridad y responsabilidad del Consejo conforme a la presente Carta para ejercer en cualquier momento la acción que estime necesaria con el fin de mantener o restablecer la paz y la seguridad internacionales.

La legítima defensa, individual o colectiva, ${ }^{72}$ prevista en el artículo glosado, es una de las posibles excepciones a la norma general de la prohibición del uso de la fuerza en las relaciones internacionales y viene referida exclusivamente frente a un ataque $\operatorname{armado}^{73} \mathrm{y}$, por ello, no cabe la denominada legítima defensa preventiva, que sería la producida por el temor a ser objeto de una agresión o ataque armado inminente. Por tanto, la legítima defensa debe configurase siempre como una reacción contra un ataque armado. Empero, no debe olvidarse que la legítima defensa

72 La legítima defensa puede ser individual o colectiva. Esta última estaría configurada por el derecho de un Estado a prestar ayuda a otro Estado, al haber sido atacado por un tercer Estado. Este tipo de legítima defensa puede resultar de un acuerdo previo de los Estados o bien de la solicitud de ayuda formulada por el Estado objeto de la agresión, "los supuestos de defensa colectiva suelen enmarcarse en una doble práctica de los Estados, de un lado, acuerdos bilaterales de ayuda mutua para supuestos en que alguno de los Estados sea objeto de ataque. El segundo mecanismo, y hoy la práctica usual y más problemática, es la existencia de mecanismos multilaterales institucionalizados. Las más significativas de dichas organizaciones están representadas por la OTAN y la UEO” (Rodríguez Carrión, A., Lecciones de derecho internacional público, Madrid, 1997, p. 534). El artículo 5 del Tratado del Atlántico Norte contiene una referencia expresa al artículo 51 de la Carta de las Naciones Unidas, "las partes convienen en que un ataque armado contra una o contra varias de ellas, acaecido en Europa o en América del Norte, se considerará como un ataque dirigido contra todas ellas y en consecuencia acuerdan que si tal ataque se produce, cada una de ellas, en ejercicio del derecho de legítima defensa individual o colectiva, reconocido por el artículo 51 de la Carta de las Naciones Unidas, asistirá a la parte o partes así atacadas, adoptando seguidamente, individualmente y de acuerdo con las otras partes, las medidas que juzgue necesarias, incluso el empleo de la fuerza armada para restablecer y mantener la seguridad en la región del Atlántico Norte".

73 Asunto de las actividades militares y paramilitares en y contra Nicaragua, CIJ, Recueil 1986, párr. 103. 
prevista en el citado artículo está pensada para los ataques armados perpetrados por las fuerzas de un Estado contra otro, pues en el momento de elaborar la carta, sus redactores tenían in mente el ataque armado en sentido clásico, sin tener en cuenta el fenómeno terrorista o "un enemigo que no es claramente identificable y sin fronteras visibles", 74 es decir, tras el 11 de septiembre se ha constatado que en el siglo XXI las amenazas a la seguridad no pueden definirse exclusivamente en términos de Estados. ${ }^{75}$

\section{A. Los atentados terroristas del 11 de septiembre ¿ataques armados?}

La legítima defensa requiere como cuestión previa la existencia de un ataque armado o agresión. Así pues, ¿los atentados terroristas del 11 de septiembre pueden calificarse como ataque armado en orden a invocar la legítima defensa? ¿Ha existido un ataque armado que legitime la invocación de la legítima defensa por parte de los Estados Unidos de América? ¿Cabe la legítima defensa contra un Estado (Afganistán) ${ }^{76}$ para responder de los atentados terroristas perpetrados por una organización terrorista cuando ni los terroristas ni quienes los han planeado tengan esa nacionalidad?

Las acciones terroristas del 11 de septiembre han sido calificadas expresamente como "ataque" por parte del Consejo de Seguridad en la Resolución 1368 (2001), pero en ningún momento añade el vocablo "armado", y recuérdese que sin ataque armado no cabe la legítima defensa. Por consiguiente, sí ha existido un ataque pero, ante el silencio del mentado órgano, procede establecer si dicho ataque puede ser considerado armado

74 Hadas, S., "La paz: una oportunidad que se escapa”, Política Exterior, 2001, núm. 84, p. 103.

75 Garrido Rebolledo, V., "Nuevas amenazas para la seguridad”, Política Exterior, 2001, núm. 84, p. 148.

76 Respecto a la situación política de Afganistán previa a los atentados terroristas del 11 de septiembre puede señalarse que los talibanes tenían diferentes frentes abiertos en una inacabable guerra civil: combatían en las provincias de Badghis y Faryab contra las fuerzas del uzbeko Dostum, en la de Bamyan contra los hazaras de Karim Khalili, en la de Ghor contra la fuerzas de Ismael Khan y en la de Badakshan contra la Alianza del Norte. En consecuencia, el régimen talibán (Emirato Islámico) no controlaba la totalidad del territorio y únicamente era reconocido como gobierno por los Emiratos Árabes Unidos y Arabia Saudita (tras los atentados estos países rompieron relaciones diplomáticas), mientras que el presidente del Estado Islámico de Afganistán, Burhanuddin Rabbani, era reconocido internacionalmente por los demás Estados (a pesar de controlar una sola provincia en el norte del país). 
o no. En este punto, pues, debe traerse a colación qué se entiende por ataque armado o agresión. ${ }^{77}$

La Resolución 3314 (XXIX), de fecha 14 de diciembre de 1974, define en su artículo 1 la agresión como "el uso de la fuerza armada por un Estado contra la soberanía, la integridad territorial o la independencia de otro Estado o en cualquier otra forma incompatible con la Carta de las Naciones Unidas, tal como se enuncia en la presente definición". A partir de la definición general puede extraerse las siguientes notas características de la agresión: a) La noción conceptual de agresión viene limitada al uso de la fuerza armada, b) La noción de agresión se aplica única y exclusivamente a las relaciones entre Estados y, por consiguiente, el uso de la fuerza armada en el interior de un Estado no entra en el área de esta definición, y c) El texto glosado guarda silencio sobre la amenaza de la fuerza armada y tal circunstancia no permite considerar la referida amenaza como agresión. En conformidad con el artículo 2, "el primer uso de la fuerza armada por un Estado en contravención de la carta constituirá prueba prima facie de un acto de agresión, aunque el Consejo de Seguridad puede concluir, de conformidad con la carta, que la determinación de que se ha cometido un acto de agresión no estaría justificada a la luz de otras circunstancias pertinentes, incluido el hecho de que los actos de que se trata o sus consecuencias no son de suficiente gravedad", y, seguidamente el artículo 3 dispone qué actos, entre otros, se caracterizarán como acto de agresión, complementando así la definición general de agresión. No obstante, tal enumeración es puramente indicativa, pues, a tenor del artículo 4, la misma "no es exhaustiva y el Consejo de Seguridad podrá determinar qué otros actos constituyen agresión, con arreglo a las disposiciones de la carta".

Los actos contemplados por el artículo 3, independientemente de que haya o no declaración de guerra, son los siguientes: a) La invasión o el ataque por las fuerzas armadas de un Estado, del territorio de otro Estado, o toda ocupación militar, aun temporal, que resulte de dicha invasión o ataque, o toda anexión, mediante el uso de la fuerza, del territorio de otro Estado o de parte de él; b) El bombardeo, por las fuerzas armadas de un Estado, del territorio de otro Estado, o el empleo de cualesquiera armas por un Estado contra el territorio de otro Estado; c) El bloqueo de los puertos o de las costas de un Estado por las fuerzas armadas de otro Estado; $d$ ) El ataque por las

77 Rambaud, P., "La définition de l'agression par 1'Organisation des Nations Unies", RGDIP, 1976, pp. 835 y ss.; Zourek, J., "Enfin une definition de l'agression”, AFDI, 1974, pp. 9 y ss. 
fuerzas armadas de un Estado contra las fuerzas armadas terrestres, navales o aéreas de otro Estado, o contra su flota mercante o aérea; $e$ ) La utilización de fuerzas armadas de un Estado, que se encuentran en el territorio de otro Estado con el acuerdo del Estado receptor, en violación de las condiciones establecidas en el acuerdo o toda prolongación de su presencia en dicho territorio después de terminado el acuerdo; f) La acción de un Estado que permite que su territorio, que ha puesto a disposición de otro Estado, sea utilizado por ese otro Estado para perpetrar un acto de agresión contra un tercer Estado.

Una vez contemplados los actos enumerados en el artículo 3, cabe descartarlos. Las fuerzas armadas de Afganistán ni invadieron ni ocuparon ni bombardearon el territorio de los Estados Unidos de América, ni sus fuerzas armadas terrestres, navales o aéreas; esto es, al adoptar el Consejo de Seguridad las Resoluciones 1368 (2001) y 1373 (2001) no sólo no establece una conexión entre los atentados terroristas y un Estado determinado (Afganistán), sino que tampoco identifica a los Estados interesados respecto del reconocido derecho inmanente a la legítima defensa. ${ }^{78}$

\section{B. Los atentados terroristas del 11 de septiembre ¿una agresión indirecta?}

En el contexto descrito, el único "clavo ardiendo" al cual agarrarse sería el referido a la sustancial participación de un Estado en dichos actos $^{79}$ (artículo 3, letra g, in fine), esto es, la denominada agresión indirecta: "el envío por un Estado, o en su nombre, de bandas armadas, grupos irregulares o mercenarios que lleven a cabo actos de fuerza armada contra otro Estado de tal gravedad que sean equiparables a los actos antes enumerados, o su sustancial participación en dichos actos". En tal sentido, la carta de 7 de octubre transmitida por el representante permanente de los Estados Unidos de América al Consejo de Seguridad señala que "la organización Al Qaeda, que recibe apoyo del régimen talibán en el Afganistán, desempeñó un papel fundamental en los ataques [y] los ataques del 11 de

\footnotetext{
78 Sobre esta cuestión, el debate en EJIL (http://www.ejil.org/forum-WTC/ny): Kirgis, F., "Addendum: Security Council adopts Resolution on combating international terrorism"; Pellet, A., "No, this is not war!", Stahn, C., "Security Council Resolutions 1368 (2001) y 1373 (2001): what they say and what they do not say".

79 Al respecto, Bermejo García, R., El Derecho..., cit., p. 16.
} 
septiembre de $2001 \ldots$ han sido posibles por la decisión del régimen talibán de permitir a esa organización que utilice como base de operaciones las partes de Afganistán que controla". ${ }^{80}$ Por su parte, en la carta entregada por el encargado de negocios interino del Reino Unido se afirma que la operación "se dirige contra la organización terrorista Al Qaeda de bin Laden y el régimen talibán que lo apoya" y, un día después, el representante permanente del Reino Unido remitió un documento en el que se indica que "el ataque no pudo haber ocurrido sin una alianza entre los talibanes y Osama bin Laden, lo cual permitió a bin Laden funcionar libremente en el Afganistán, promoviendo, planificando y ejecutando actividades terroristas". ${ }^{81}$ Por consiguiente, ¿ha tenido Afganistán una sustancial participación en los actos terroristas del 11 de septiembre? ¿Puede considerarse "sustancial" que Afganistán haya permitido que en su territorio se desarrollara la estructura de la organización Al Qaeda? ¿Es "sustancial" que Osama Bin Laden fuera un invitado del gobierno talibán?

Si las respuestas a las cuestiones planteadas son afirmativas, ${ }^{82}$ el derecho a la legítima defensa de los Estados Unidos de América ha sido utilizado en buena lid. Sin embargo, la actitud del régimen talibán respecto a Osama Bin Laden o Al Qaeda, si bien es contraria al derecho internacional ${ }^{83}$ y condenable, no es suficiente para fundamentar y sostener la existencia de una agresión indirecta. Los terroristas del 11 de septiembre no actuaron bajo la dirección del Estado afgano (régimen talibán) ni los atentados revelaron una sustancial participación de dicho Estado en algo más allá que la posible mera asistencia logística. En concreto, atendiendo a lo declarado por el TIJ en el Asunto de las actividades militares y paramilitares en y contra Nicaragua, ${ }^{84}$ sería necesario probar que Afganistán

80 Doc. S/2001/946.

81 Docs. S/2001/947 y S/2001/949, respectivamente.

82 Sobre esta cuestión, Gutiérrez Espada, C., “¿No cesaréis de citarnos leyes viendo que ceñimos espada? (a propósito del 11-S)”, ADI, 2001, vol. XVII, p. 33.

83 "Todo Estado tiene el deber de abstenerse de organizar o fomentar la organización de fuerzas irregulares o de bandas armadas, incluidos los mercenarios, para hacer incursiones en el territorio de otro Estado" (párrafo 8) y "todo Estado tiene el deber de abstenerse de organizar, instigar, ayudar o participar en actos de guerra civil o en actos de terrorismo en otro Estado o de consentir actividades organizadas dentro de su territorio encaminadas a la comisión de dichos actos, cuando los actos a que se hace referencia en el presente párrafo impliquen el recurrir a la amenaza o al uso de la fuerza" (párrafo 9) de la Resolución 2625 (XXV), adoptada por la Asamblea General el 24 de octubre de 1970.

84 CIJ, Recueil 1986, pp. 64 у 65. 
tenía el control efectivo de la operación terrorista y, hasta este momento, tal cosa no ha sido probada. Por ello, actualmente, la actuación del gobierno talibán de Afganistán no puede ser calificada de participación sustancial en los actos perpetrados el 11 de septiembre por la organización Al Qaeda. Por otra parte, si bien el Consejo de Seguridad ${ }^{85}$ ha condenado la conducta del régimen talibán "por haber permitido que el Afganistán fuera utilizado como base para la exportación del terrorismo por la red Al-Qaida y otros grupos terroristas y por haber amparado a Osama Bin Laden, Al-Qaida y otros asociados" (Resolución 1378 (2001), de 6 de diciembre), no es menos cierto que en ninguna resolución se ha pronunciado expresamente sobre la responsabilidad de Afganistán por los ataques del 11 de septiembre. ${ }^{86}$ En consecuencia, "la complicidad del régimen talibán, el auxilio, refugio o cualquier clase de apoyo que haya podido prestar Al Qaeda, a los autores, no basta, según los precedentes conocidos del Consejo de Seguridad y la Corte Internacional de Justicia, para plantear la reacción en términos de legítima defensa". ${ }^{87}$

Descartados los supuestos enumerados en el artículo 3 la Resolución 3314 (XXIX), en tanto que los actos terroristas, calificados como ataque por el Consejo de Seguridad, no tienen cabida entre los mismos, hay que

85 Tras la operación Alcance Infinito, en la Resolución 1214 (1998), de 8 de diciembre, el Consejo de Seguridad se confiesa "profundamente perturbado porque continúe utilizándose el territorio afgano, en particular las zonas controladas por los talibanes, para albergar y adiestrar a terroristas y planificar actos terroristas" y exige que "los talibanes se abstengan de dar santuario y adiestrar a terroristas internacionales y sus organizaciones, y que todas las facciones afganas cooperen con los esfuerzos para enjuiciar a los inculpados de actos terroristas". Posteriormente, en la Resolución 1267 (1999), de 15 de octubre, el Consejo de Seguridad inculpa al régimen talibán de proteger las actividades terroristas de Osama bin Laden y ordena su entrega a los Estados Unidos de América o a cualquier otro Estado interesado en su persecución penal en el término de un mes o, en caso contrario, se adoptarán sanciones tanto financieras como en el ámbito del transporte aéreo. En la Resolución 1333 (2000), de 19 de diciembre, el Consejo de Seguridad califica el incumplimiento de sus mandatos por el régimen talibán de "amenaza a la paz y seguridad internacionales" y, en el marco del capítulo VII de la carta, ordena a dicho régimen que adopte las medidas apropiadas para que en el territorio bajo su control no se entrenen terroristas y, además, entregue a Osama bin Laden a Estados Unidos de América u otro Estado en orden a su enjuiciamiento.

86 Señalar que, según el artículo 11 del proyecto de artículos sobre responsabilidad internacional de los Estados, el comportamiento que no sea atribuible al Estado en virtud de los artículos indicados del proyecto se considerará, no obstante, hecho de ese Estado según el derecho internacional en el caso y en la medida en que el Estado reconozca y adopte ese comportamiento como propio; pues bien, Afganistán no sólo no ha reconocido la autoría de los ataques del 11 de septiembre, sino que el nuevo gobierno del país ha declarado, con motivo de la conferencia diplomática celebrado en Bonn en diciembre del 2001, que entregará a la justicia a Osma Ben Laden y Moullah Oamar.

87 Remiro Brotóns, A., Estados Unidos..., cit., p. 117. 
traer a colación su artículo 4, pues en él se estipula que el Consejo de Seguridad podrá determinar qué otros actos constituyen agresión, con arreglo a las disposiciones de la carta. ¿Ha determinado el Consejo de Seguridad que los atentados terroristas del 11 de septiembre constituyen actos de agresión? La respuesta no es clara. En principio pudiera ser que el Consejo de Seguridad haya iniciado este camino y la mención a la legítima defensa en las resoluciones 1368 (2001) y 1373 (2001) fuera un inicio de equiparación entre los actos terroristas y el ataque armado de un Estado. En este sentido, algunos iusinternacionalistas ${ }^{88}$ han sostenido que dichas resoluciones conllevan una ampliación del concepto de legítima defensa cuando ésta se utilice frente a atentados de grandes dimensiones, tales como los acontecidos el 11 de septiembre en Estados Unidos de América o el 11 de marzo en España (Madrid). Ahora bien, atendiendo a la configuración legal actual de la legítima defensa, debe advertirse que la Resolución 1368 (2001) no califica los atentados como "ataques armados", que sería lo requerido para aplicar la legítima defensa prevista en el artículo 51 de la carta, y además dicho derecho está pensado para ejercitarse frente a los ataques de otros Estados y no respecto de los perpetrados por organizaciones terroristas. Además, debe recordarse que la legítima defensa no es mencionada en la Resolución 56/1, de 12 de septiembre del 2001, adoptada por la Asamblea General y en cuyo texto se condena los ataques del 11 de septiembre. En todo caso, habrá que esperar a futuras resoluciones del Consejo de Seguridad sobre la materia, pero a la luz de lo indicado, y en orden a la aplicación de la legítima defensa frente a los atentados perpetrados por grupos terroristas, cabe señalar que debería operarse una doble exigencia, a saber: 1) Ampliar la noción de ataque armado incluyendo entre sus modalidades los ataques terroristas ${ }^{89} \mathrm{y}$ 2) La posibilidad de atribuir el ataque terrorista a un Estado cuando éste permita la utilización de su territorio al grupo terrorista autor material del mismo. ${ }^{90}$

8 Por ejemplo, Condorelli, L., Les attentats..., cit., p. 843.

89 Reisman, W., "In defense of world public order", AJIL, 2001, vol. 95, pp. 833-835.

90 Byers, M., "Terrorism, the use of force and international law after 11 september", ICLQ, 2002, vol. 51, pp. 406-410 y Cassese, A., Terrorism..., cit., pp. 993 y ss. 


\section{C. ¿Fue la respuesta estadounidense inmediata, necesaria y proporcional?}

El ejercicio del derecho de legítima defensa está presidido por varios requisitos o condiciones y, así, la respuesta ante un ataque armado tiene que revestir un carácter inmediato, ser necesaria y proporcional. En primer lugar, la reacción frente al ataque armado debe ser inmediata en el tiempo, porque el uso de la fuerza en defensa sólo está justificado en tanto que es necesario para repeler dicho ataque (ataque armado en curso). Pues bien, la respuesta estadounidense se produce 26 días después de los atentados perpetrados por Al Qaeda en territorio estadounidense, es decir, la respuesta defensiva se llevó a término en un momento muy posterior a aquellos. ${ }^{91}$ No obstante, si bien podría argumentarse que este lapsus de tiempo fue necesario para preparar la defensa, ${ }^{92}$ debe recordarse 1) Que la imputación de los atentados a Al Qaeda se realizó el mismo día 11 por el coordinador del Consejo Nacional de Seguridad y fue confirmada al día siguiente por la CIA, y 2) Los planes de la operación Libertad Duradera ya habían sido elaborados bajo la administración Clinton. ${ }^{93}$ Por tanto, cabe sostener que en la respuesta armada no concurrió la condición de inmediatez.

En segundo lugar, debe existir una proporcionalidad entre el ataque armado y la respuesta del Estado objeto de la agresión (principio de la proporcionalidad), consistente en que la acción defensiva tiene que estar en relación con el objetivo que se pretende alcanzar - detener o repeler un ataque armado y asegurarse de su no repetición-, es decir, tiene que limitarse a lo estrictamente necesario en relación con el fin perseguido o, dicho según la clásica fórmula, "el acto justificado por la necesidad de defensa propia debe limitarse por esa necesidad y mantenerse claramente dentro de ella" ${ }^{94} \mathrm{Si}$ bien en la carta remitida al Consejo de Seguridad por el representante permanente estadounidense se afirmaba que los "Estados Unidos han contraído

91 Sobre esta cuestión, Charley, J., "The use of force against terrorism and international law", AJIL, 2001, vol. 95, pp. 835 y 836.

92 Escribe Ortega Carcelén que "la inmediatez subsiste durante la preparación para la defensa, pero no más allá" y transcurrido ese tiempo "la fuerza ya no se usa para repeler un ataque, sino para otros fines" (una represalia armada) (Ortega Carcelén, M., La legítima defensa del territorio del Estado, Madrid, 1991, pp. 86 y 98.

93 Escribe Clarke, coordinador del Consejo de Seguridad Nacional durante las administraciones de Clinton y Bush, que los planes de esta campaña militar "habían sido preparados, pero no utilizados, durante la administración Clinton” (Clarke, R., Contra ..., cit., p. 340).

94 Asunto de las actividades militares y paramilitares en y contra Nicaragua, CIJ, Recueil 1986, párr. 224. 
el compromiso de causar el mínimo de víctimas civiles y daños a las propiedades civiles", ${ }^{95}$ la operación se realizó mediante ataques aéreos y bombardeos sistemáticos sobre los campamentos del grupo terrorista y las instalaciones militares e instituciones políticas del régimen talibán, ${ }^{96}$ causando daños colaterales en bienes y personas civiles en incumplimiento de las disposiciones del derecho internacional humanitario, para finalmente no capturar a bin Laden.

Por último, en tercer lugar, la respuesta debe ser necesaria para detener el ataque, es decir, que se constituya como el único medio razonable para repeler el ataque armado. Estados Unidos de América podría haber instado una resolución del Consejo de Seguridad en orden a la autorización del desencadenamiento de las medidas del artículo 42 de la carta, máxime cuando dada la situación existente con casi plena seguridad ningún miembro permanente hubiera ejercitado el veto. Así, la "legítima defensa" justificada por los Estados Unidos de América no constituía el único medio para poner fin a la situación y, en su caso, prevenir futuros ataques contra los intereses estadounidenses.

En el supuesto de que no concurran estos requisitos, no se estará ante un supuesto de legítima defensa y la apreciación de éstos en función de las circunstancias del supuesto concreto - respuesta estadounidense- permiten sostener que los mismos no concurrieron, ${ }^{97}$ ya que no se dio la inmediatez ni la proporcionalidad como tampoco la necesariedad.

\section{D. ¿Fue la respuesta estadounidense provisional?}

El artículo 51 de la carta dispone que el Estado que responde a un ataque armado mediante el ejercicio del derecho de legítima defensa tiene la doble obligación de informar al Consejo de Seguridad sobre las medidas defensivas adoptadas y subordinar su actuación a lo que disponga dicho órgano. Respecto a la primera obligación, cabe advertir que la información proporcionada por Estados Unidos de América y sus aliados al Consejo de Seguridad ${ }^{98}$ es prácticamente inexistente, limitándose en

95 Doc. S/2001/946.

96 Al respecto, Mcinnes, C., A different..., cit., pp. 165 y ss.

97 Sobre esta cuestión, Cassese, A., Terrorism..., cit., pp. 997 y 998; González Vega, J., "Los atentados del 11 de septiembre, la operación 'libertad duradera' y el derecho de legítima defensa", REDI, 2001, núms. 1 y 2 , pp. 247 y ss.

98 Una vez iniciada la operación Libertad Duradera, el Consejo de Seguridad no se reunió para tratar cuestiones relativas a la misma hasta el día 12 de noviembre en que adoptó la Resolución 
buena medida a lo escuetamente comunicado en las cartas entregadas el 8 de octubre. Así, el referido órgano ni ha controlado ni ha analizado las acciones bélicas llevadas a término en Afganistán. Sin embargo, al tenor de lo dispuesto por el Tribunal Internacional de Justicia, ${ }^{99}$ esta ausencia de información no conlleva que la respuesta defensiva se convierta en ilícita.

En cuanto a la segunda obligación, el ejercicio del derecho de legítima defensa es provisional, ya que la defensa sólo es legítima en tanto que el Consejo de Seguridad haya tomado las medidas necesarias para mantener la paz y la seguridad internacionales. Así pues, la cuestión a establecer es el momento a partir del cual el derecho de legítima defensa deja de existir en beneficio del Consejo de Seguridad. En principio, la respuesta es clara: el derecho a ejercer la legítima defensa deja de existir en beneficio de las competencias del Consejo de Seguridad cuando éste ha adoptado "las medidas necesarias para mantener la paz y la seguridad internacionales". En este sentido, dicho órgano habrá adoptado tales medidas cuando haya reaccionado con alguna acción positiva con el fin de hacer frente a la situación y sustituirse así en la acción del país objeto del ataque armado:

La legítima defensa se justifica, dentro de un sistema de seguridad colectiva, por el hecho de que el ataque armado, la agresión, está en curso y ha de atajarse en tanto las instituciones comunes toman las medidas pertinentes. Esta circunstancia no se produce habitualmente en los actos terroristas. Reaccionar frente a ellos utilizando la fuerza en el país que los alberga, sin autorización del Consejo de Seguridad, puede ser un acto de represalia, no de legítima defensa. Pero las represalias armadas son también incompatibles con las obligaciones de los miembros de la ONU.100

Por tanto, la legítima defensa es "siempre una excepción dentro de un sistema en que la fuerza, el poder coercitivo, está depositado en instituciones comunes, en nuestro caso el Consejo de Seguridad". ${ }^{101}$

Una vez producido el ataque terrorista del 11 de septiembre, cabe advertir que el Consejo de Seguridad no adoptó en ningún momento las

1378 (2001) y trató de forma "secundaria" el tema. En las reuniones posteriores sobre Afganistán el tema no fue tratado en ninguna ocasión.

99 Asunto de las actividades militares y paramilitares en y contra Nicaragua, CIJ, Recueil 1986, p. 105.

100 Remiro Brotóns, A., Estados..., cit., pp. 117 y 118.

101 Remiro Brotóns, A., El orden..., cit., p. 155. 
medidas necesarias para mantener la paz y la seguridad internacionales, es decir, las dispuestas en el artículo 42 de la carta. Empero, a mayor abundamiento, en este contexto, el gobierno de los Estados Unidos de América repitió hasta la saciedad que utilizarían su derecho a la legítima defensa mientras necesitaran llevar a cabo acciones. A título de ejemplo, en una carta dirigida al presidente del Consejo de Seguridad se afirma que "todavía es mucho lo que no conocemos... y podemos encontrarnos con que nuestra legítima defensa requiera nuevas acciones contra otras organizaciones y otros Estados". ${ }^{102}$

\section{2. ¿La defensa preventiva como una lex specialis?}

Al tenor del derecho internacional vigente en el momento de los atentados terroristas del 11 de septiembre, no cabe el derecho de legítima defensa por parte de los Estados Unidos de América contra Afganistán, ${ }^{103}$ pues a éste último no le ha sido imputada la autoría (ni agresión directa ni indirecta) del ataque... que tampoco es "armado". El Consejo de Seguridad no califica en la Resolución 1368 (2001) los actos terroristas como "ataques armados" (que justificaría la aplicación de la legítima defensa prevista en el artículo 51), mientras que sí los califica de amenaza a la paz internacional. Así, cabe advertir que la respuesta armada de los Estados Unidos de América se enmarca claramente en la figura de la defensa preventiva y, sin embargo, pareció contar con el asentimiento del Consejo de la OTAN, ${ }^{104}$ la Unión Europea, etc. Ante esta circunstancia, todo parecía indicar que se estaba generando una tendencia a admitir como lex specialis - generada consuetudinariamente - la defensa preventiva para los supuestos en que se hubiera de hacer frente a atentados terroristas susceptibles de ser calificados como de gran envergadura y, de esta forma, los Estados podrían actuar sobre la base de una nueva modalidad del derecho de legítima defensa ${ }^{105}$ en tanto que la noción de ataque armado comprendería los atentados terroristas de relevancia mundial. ${ }^{106}$ Por consiguiente, ¿se está ante una práctica capaz de

102 Doc. S/2001/1946, de 7 de octubre.

103 Gutiérrez Espada, C., “¿No cesaréis...”, cit., p. 34; Kohen, M., "L'arme de civilisation, c'est le droit", Le Temps, 17 de septiembre del 2001, p. 7; Remiro Brotóns, A., Estados..., cit., pp. 114 y ss.

104 Esta posibilidad está avalada por el comunicado, de fecha 2 de octubre del 2001, de la OTAN en el que declaraba aplicable el artículo 5 de su tratado constitutivo.

105 Condorelli, L., Les attentats..., cit., p. 843.

106 "De ser así, habría que trazar los límites y las condiciones en que los Estados podrían recurrir a la fuerza en estos casos; de lo contrario se abriría la puerta a posibles acciones decididas unilateralmente 
generar una norma in statu nascendi, en atención a la cual se podría invocar la legítima defensa sin necesidad de la existencia de un ataque armado?

A la vista de la actuación del Consejo de Seguridad, parece que éste acepta la respuesta armada de los Estados Unidos de América como un ejercicio del derecho a la legítima defensa reconocido en las Resoluciones 1368 (2001) y 1373 (2001), pues no sólo omitió sus funciones en relación con el uso de la fuerza armada, sino que además, el 14 de noviembre del 2001, reafirmó dichas resoluciones y apoyó "los esfuerzos internacionales encaminados a erradicar el terrorismo, de manera acorde con la Carta de las Naciones Unidas", Resolución 1378 (2001). ${ }^{107}$ Y, a mayor abundamiento, el 20 de diciembre del 2001, acogió complacido "la evolución de los hechos en Afganistán" (Resolución 1386 (2001). Por consiguiente, el citado órgano reconoce - legaliza - el ejercicio de la legítima defensa desarrollado por los Estados Unidos de América a través de la operación Libertad Duradera. Asimismo, el secretario general, Kofi Annan, declaró el 8 de octubre que el Consejo de Seguridad "reafirmó el derecho inherente a la legítima defensa individual o colectiva de acuerdo con la Carta de las Naciones Unidas. Siguiendo este contexto los Estados afectados han dispuesto sus acciones militares actuales en Afganistán".

Afirmar la existencia de legítima defensa en el caso analizado conlleva una desnaturalización del concepto de esta institución previsto en el artículo 51 de la carta: una ampliación del concepto de legítima defensa individual o colectiva para los casos — ataques - más graves de terrorismo no atribuibles a un Estado. Ahora bien, de ser cierta esta posibilidad, como advierte Gutiérrez Espada, se trata de "una ampliación del derecho de legítima defensa no prevista ni aceptada, salvo por un número muy reducido de Esta-

por los Estados más poderosos con el pretexto de la lucha contra el terrorismo. Parece evidente que, además de los requisitos exigidos por la doctrina tradicional de la legítima defensa, sería necesaria en estos casos una respuesta multilateral y una amplia aprobación de la comunidad internacional" (Casanovas y La Rosa, O., "El principio de la prohibición del uso de la fuerza", en varios autores, Instituciones de derecho internacional público, Madrid, 2003, p. 920).

107 "El Consejo de Seguridad de las Naciones Unidas no autorizó expresamente la denominada "Operación Libertad Duradera" consistente en el ataque armado contra el régimen de los talibanes por parte de una coalición de Estados encabezada por los Estados Unidos, y cuya finalidad era derrocar dicho régimen, eliminar la red terrorista Al-Qaida y detener a Osama bin Laden. Sin embargo, nada más empezar dicha operación, el 14 de diciembre de 2001, sí que expresará su apoyo a los esfuerzos encaminados a establecer una administración nueva y de transición que conduzca a la formación de un nuevo gobierno en Afganistán, a través de la resolución 1378 (2001)" (Cardona Llorens, J., "La Resolución 1386 (2001) del Consejo de Seguridad autorizando la fuerza internacional de asistencia para la seguridad de Afganistán: ¿Un paso más en el debilitamiento de las Naciones Unidas?", Revista Española de Derecho Internacional, 2001, núms. 1 y 2, p. 228). 
dos (Estados Unidos de América, Israel, África del Sur), hasta hoy". ${ }^{108}$ Por su parte, Remiro Brotóns escribe que "si ahora Estados Unidos de América (y Gran Bretaña) aducen legítima defensa y todas las instituciones con atribuciones para pronunciarse otorgan, habrá que reconocer que ahora a eso, esto es, la operación militar desencadenada como consecuencia de atentados terroristas imputados a actores no estatales (Al-Qaida) con la complicidad de gobiernos no reconocidos (talibanes) de Estados miembros de las Naciones Unidas (Afganistán) se le llama legítima defensa" ${ }^{109}$

En este contexto y sobre la posible desnaturalización del derecho a la legítima defensa, cabe recordar la polémica suscitada por la Resolución 678, de 28 de noviembre de 1990, del Consejo de Seguridad — que autorizaba a los Estados miembros que cooperaban con el gobierno de Kuwait para que utilizaran "todos los medios necesarios para hacer valer y llevar a la práctica la Resolución 660 (1990) y todas las resoluciones pertinentes que la siguieron y para restablecer la paz y la seguridad internacionales en la región"¿Actuaba el Consejo de Seguridad en sede del artículo 42 o del artículo 51 de la carta? La correcta respuesta a la cuestión planteada solamente podía venir dada por el propio Consejo de Seguridad, pero de su ambigua actuación durante la crisis del Golfo Pérsico no se deducía de forma fehaciente si la Resolución 678 (1990) era una manifestación "original de la legítima defensa colectiva" 110 o bien recogía en su seno el texto del artículo 42 de la carta. Para determinados autores, la Resolución 678 (1990) fue adoptada en el ámbito del artículo 51, ya que ante la tendencia a desviarse de los procedimientos del capítulo VII de la carta, se organizó "una operación paralela, según el artículo 51 de la carta — que estipula el derecho inherente a la autodefensa individual o colectiva- e independiente de las decisiones del Consejo de Seguridad". ${ }^{111}$ Así pues, entendía este sector doctrinal que "el derecho de legítima defensa colectiva previsto en el artículo 51, que había sido suspendido por la acción del Consejo de Seguridad en consonancia con la Resolución 661, se restableció por la Resolución 678". ${ }^{112}$ Por tanto, aten-

\footnotetext{
108 Gutiérrez Espada, C., “¿No cesaréis...”, cit., p. 37. Al respecto, Gaja, G., “In what sense was there an 'armed attack", EJIL (http://www.ejil.org/forum-WTC/ny).

109 Remiro Brotóns, A., El orden..., cit., p. 155.

110 Sánchez Rodríguez, L., "La invasión de Kuwait por Irak y la acción del Consejo de Seguridad de las Naciones Unidas", Cursos de derecho internacional de Vitoria Gasteiz, Bilbao, 1991, p. 57.

111 Urquhart, B., "Lecciones del Golfo", Debats, mayo/junio de 1991, p. 125.

112 Zacklin, R., "Les Nations Unies et la crise du Golfe", Les aspects juridiques de la crise et de la guerre du Golfe, París, 1991, p. 69.
} 
diendo a este planteamiento, la base jurídica de la resolución comentada se encontraba en el artículo 51 de la carta. ${ }^{113}$

Por su parte, Carrillo Salcedo señaló que la Resolución 678 (1990) "legitimó la acción colectiva de fuerza armada de los Estados que cooperaron con Kuwait, pero no supuso un uso institucionalizado de la fuerza armada, es decir, una respuesta institucionalizada de la comunidad internacional frente al agresor". ${ }^{114}$ La resolución comentada, en un intento de legitimar la decisión de recurrir a la fuerza armada adoptada fuera del marco de las Naciones Unidas, implicaba un abandono de la institucionalización del uso de la fuerza en el ámbito de las relaciones internacionales, ya que "no se procedió a una aplicación estricta del artículo 42 de la carta, esto es, a la aplicación de medidas colectivas armadas bajo la autoridad del Consejo de Seguridad con la ayuda del Comité de Estado Mayor, sino a una especie de autorización de medidas de legítima defensa colectiva, casi en el marco del artículo 51 de la carta" o, dicho de otro modo, la Resolución 678 (1990) conllevaba "la reintroducción, de modo subrepticio y con muy dudoso fundamento jurídico, del derecho inmanente de legítima defensa colectiva, en condiciones muy distintas de las previstas y reguladas en el artículo 51 de la Carta de las Naciones Unidas". ${ }^{115}$ En otras palabras, el Consejo de Seguridad habría autorizado una "especie" de legítima defensa colectiva.

En principio, la opción de la aplicación de una "desnaturalizada" legítima defensa colectiva vendría sustentada por la existencia de un ataque armado (agresión de Irak a Kuwait); la referencia de la Resolución 661 (1990) al artículo 51 de la carta; y la equívoca redacción de la Resolución 678 (1990) sobre la cooperación de los Estados con Kuwait. Estas circunstancias apoyan la idea de legítima defensa colectiva y, como escribió Sánchez Rodríguez, "la originalidad residiría en este caso... en que vendría avalada para los Estados intervinientes por decisiones del propio Consejo de Seguridad". ${ }^{116}$

A la luz de las circunstancias apuntadas y de la posterior actuación desarrollada, si bien en un principio parecía que la opción elegida por el Con-

113 Sobre esta cuestión, Gaja, G., "Il Consiglio di Sicurezza di fronte all'occupazione del Kuwait: il significato di una autorizzazione", $R D I, 1990$, pp. 696 y ss.; Luzzatto, R., "Le guerre e il diritto internazionale", Il Corriere Giuridico, 1991, pp. 245 y ss.; y Schachter, O., "United Nations law in the Gulf conflict", AJIL, 1991, pp. 452 y ss.

114 Carrillo Salcedo, J., "Las Naciones Unidas ante la década de los noventa", Cursos de derecho internacional de Vitoria Gasteiz, Bilbao, 1990, p. 51.

115 Carrillo Salcedo, J., Curso de derecho internacional público, Madrid, 1994, pp. 224 y 225.

116 Sánchez Rodríguez, L., La invasión..., cit., p. 57. 
sejo de Seguridad consistía en autorizar una especie de legítima defensa colectiva, posteriormente tal posibilidad no se concretó y se decantó por el artículo 42: la Resolución 678 (1990) afirma genéricamente que dicho órgano actúa "con arreglo al capítulo VII de la carta" 117 y, en consecuencia, aunque no se cite de forma expresa, el mentado órgano actúa de conformidad con el artículo 42 de dicho texto legal, cuyas medidas pueden llevarse a término por la vía dispuesta en los artículos 43 a 47 o, en su caso, por la del artículo 48, todos del citado cuerpo jurídico.

Finalmente, en el sentir de otros autores, ${ }^{118}$ la Resolución 678 (1990) implicó dejar las acciones bélicas contra Irak al margen del sistema institucional previsto en la Carta de las Naciones Unidas, tanto por el oscuro papel del Consejo de Seguridad en la dirección y el control de las operaciones militares como por su difícil encuadre en el artículo 42 o en el artículo 51 de la carta.

\section{La operación Libertad Duradera ¿legítima defensa preventiva?}

En el desarrollo de la operación Libertad Duradera, cabe advertir que no concurrieron las condiciones inherentes al ejercicio del derecho de la legítima defensa. No existió un ataque armado previo, al igual que tampoco cabe sostener la existencia de una agresión indirecta por parte de Afganistán, ni tampoco la intervención estadounidense se llevó a término de conformidad con los requisitos propios del ejercicio del derecho de legítima defensa. A mayor abundamiento, la actuación estadounidense $-\mathrm{y}$ de su socio el Reino Unido- tampoco se realizó en el marco de una respuesta institucional patrocinada por las Naciones Unidas en el marco del artículo 42 de la carta. Por consiguiente, la respuesta estadounidense se ejercitó al margen del marco jurídico de la carta y, por tanto, cabe englobarla en la esfera de la llamada legítima defensa preventiva, circunstancia ésta que permite sostener

117 La base legal sobre la que actúa el Consejo de Seguridad para aprobar la resolución es el capítulo VII de la carta pero no menciona o precisa el artículo o artículos concretos del mismo. Ahora bien, esta postura o ausencia de referencia al artículo 42 - como la no mención expressis verbis del artículo 41 en la Resolución 661 (1990) — responde a la práctica seguida por el Consejo de Seguridad, "que en toda su historia sólo se ha referido en una ocasión expresamente a los artículos 41 o 42, a saber, la mención al artículo 41 en su Resolución 232 sobre las sanciones a Rhodesia” (Dastis Quecedo, A., "El uso de la fuerza armada en el Golfo: una justificación jurídica", REDI, 1991, núm. 1, p. 112). En todo caso, como señala Andrés Sáenz de Santa María, el uso de la fuerza contra Irak nos "coloca, en efecto, ante los artículos 42 y siguientes" (Andrés Sáenz de Santa María, M., "Réplica: cuestiones de legalidad en las acciones armadas contra Irak", REDI, 1991, núm. 1, p. 118).

118 Andrés Sáenz de Santa María, M., Replica..., cit., p. 117. 
que dicha acción constituye un uso grave de la fuerza contra un tercer Estado, es decir, una represalia $\operatorname{armada}^{119}$ — contra un Estado que cobija terroristas - que contradice el espíritu y la letra de la Carta de las Naciones Unidas en tanto que viola su artículo 2.

\section{LA SOLUCIÓN “CORRECTA” DEL “CONFLICTO AFGANO”}

En el caso de la acción bélica en Afganistán, tras la faz de la seguridad nacional y la legítima defensa invocada, puede advertirse con Remiro Brotóns que "la operación militar de Estados Unidos de América (y sus aliados) es la venerable autotutela o autodefensa, la institución en cuya virtud cada Estado, por sí o mediante las oportunas alianzas, persigue la satisfacción de sus intereses, recurriendo eventualmente a la fuerza armada". ${ }^{120}$ Así, por consiguiente, la intervención estadounidense, al no observar las previsiones de la carta a propósito del ejercicio de la legítima defensa, ha llevado a término una acción de defensa preventiva que es contraria a la Carta de las Naciones Unidas.

Si bien es cierto que los condenables atentados del 11 de septiembre no sólo dieron autoridad moral para intervenir sino también el derecho de defenderse, tal defensa debía llevarse a cabo en el marco de las Naciones Unidas y de conformidad a la legalidad de la carta, pues como afirma Jacques Chirac, este órgano internacional "es el único legítimo para construir la paz en todas partes". ${ }^{121}$ ¿Qué tipo de reacción se hubiese conformado a la legalidad de la carta? En palabras de Pastor Ridruejo:

La respuesta es fácil. Ese modo de reacción no era otro, a mi entender, que la acción institucional prevista para los casos de amenazas a la paz, quebrantamientos de la paz o actos de agresión en el Capítulo VII de la carta. $\mathrm{Y}$ es del todo verosímil que, de la misma manera que los Estados Unidos de América consiguieron la unanimidad de los miembros del Consejo para la adopción de las resoluciones 1368 y 1373 y otras, hubiesen obtenido la misma actitud unánime para la autorización del desencadenamiento de una acción armada. Pero los Estados Unidos de América decidieron orillar y menospreciar una vez más al Consejo de Seguridad; en aras de sus intereses de poder prefirieron el unilateralismo al multilateralismo, lo que cierta-

119 Al respecto, Remiro Brotóns, A., El orden..., cit., p. 156.

120 Remiro Brotóns, A., Estados Unidos..., cit., p. 119.

121 La Vanguardia, 21 de marzo del 2003. 
mente hace perder autoridad y credibilidad a las Naciones Unidas en su función primera y primordial de mantenimiento de la paz y seguridad internacionales. ${ }^{122}$

En relación con lo afirmado in fine, señalar que:

La respuesta militar a los atentados desencadenada por los Estados Unidos de América plantea, una vez más y con toda agudeza, cuál es el papel que corresponde a la Organización de las Naciones Unidas para que sea eficaz el mantenimiento de la paz y la seguridad internacionales; y pone de relieve, al mismo tiempo, los riesgos que entrañan las acciones unilaterales en este ámbito aun cuando luego sean "convalidadas" por actos de dicha organización, pues de consolidarse esta práctica ello puede suponer, en última instancia, una verdadera "mutación constitucional" del sistema previsto en la Carta de las Naciones Unidas. ${ }^{123}$

\section{LA LEGÍTIMA DEFENSA PREVENTIVA COMO DOCTRINA ESTRATÉGICA DE SEGURIDAD}

La Estrategia de Seguridad Nacional de los Estados Unidos de América, adoptada por la administración Bush, se fundamenta en la denominada legítima defensa preventiva: "cuanto mayor sea la amenaza, tanto mayor es el riesgo si no se actúa, y con mayor motivo se impone que nos anticipemos en nuestra defensa, incluso si no sabemos cuándo y dónde atacará el enemigo. Los Estados Unidos, si es necesario, actuarán preventivamente para impedir o prevenir estos actos hostiles de nuestros adversarios". ${ }^{124}$ Así, los Estados Unidos de América ${ }^{125}$ podrán utilizar la fuerza armada ante el temor de un ataque previsible e inminente, pero que aún no se ha producido, es decir, el

122 Pastor Ridruejo, J., Curso..., cit., p. 729. En este sentido, Remiro Brotóns, A., El orden..., cit., p. 158.

123 González Campos, J; Sánchez Rodríguez, L. y Andrés Sáenz de Santa María, M., Curso..., cit., p. 28.

124 The White House, The National Strategy of the Unitet States, Washington, septiembre del 2002, p. 15.

125 En relación con la intervención armada en Afganistán, el presidente Bush tenía expresa autorización del Senado para, sobre la base del derecho a la legítima defensa y de la amenaza a la seguridad nacional, "usar toda la fuerza necesaria y apropiada contra aquellos países, organizaciones o personas que en su opinión planearon, autorizaron, ejecutaron o ayudaron a realizar los ataques terroristas o acogieron a tales organizaciones o personas" (Senado de los Estados Unidos: US Senate Joint Resolution 23, de 14 de septiembre del 2001). 
ejercicio de la fuerza se realiza con anterioridad a un ataque con el objeto de que éste no llegue a producirse.

Esta doctrina estratégica para proteger la seguridad nacional estadounidense no tiene acomodo en el derecho internacional general ni está autorizada en el artículo 51 con la Carta de las Naciones Unidas, ${ }^{126}$ ya que obvia la existencia de un ataque armado previo, requisito este último del todo necesario - conditio sine qua non - para que pueda ejercitarse el derecho de legítima defensa. Por consiguiente, de admitirse la legítima defensa preventiva, ${ }^{127}$ como advierten González Campos, Sánchez Rodríguez y Sáenz de Santa María, "se estaría abriendo la puerta a calificaciones arbitrarias de los Estados para legitimar el uso de la fuerza ante un ataque todavía inexistente, lo que sería contrario al principio general de prohibición del uso de la fuerza y desnaturalizaría por completo el papel hegemónico del Consejo de Seguridad en el contexto del artículo 51 de la carta". ${ }^{128}$ Asimismo, bajo el pretexto de la legítima defensa preventiva, cabe la posibilidad de encubrir acciones bélicas que constituyen verdaderas agresiones a otro Estado.

Por otra parte, la citada estrategia no supone nada nuevo, pues la misma confirma la práctica llevada a cabo por los Estados Unidos de América. Así, por ejemplo, la operación Alcance Infinito, ordenada por el ex presidente Clinton, fue justificada acudiendo a la legítima defensa, ${ }^{129}$ tal como se afirmaba en la carta, de 20 de agosto de 1998, dirigida por el embajador estadounidense en Naciones Unidas al presidente del Consejo de Seguridad: "Estados Unidos ha actuado de acuerdo con el derecho de legítima defensa confirmado por el artículo 51 de la Carta de las Naciones Unidas. Los objetivos, el momento y el método de ataque fueron cuidadosamente elegidos para minimizar los riesgos de daños colaterales a civiles y respetar el derecho internacional, incluidas las reglas de necesidad y proporcionalidad". Y, poco después, el subsecretario de Estado para asuntos políticos, Thomas

126 Pastor Ridruejo, J., Curso..., cit., pp. 609-611.

127 Por ejemplo, la legítima defensa preventiva fue invocada por Israel cuando, el día 7 de junio de 1981, su aviación destruyó el reactor nuclear situado en la ciudad iraquíana de Osirak; ni la Asamblea General que calificó el acto de agresión, ni el Consejo de Seguridad aceptaron la excusa alegada por las autoridades israelitas de que utilizaban el derecho de legítima defensa individual previsto en el artículo 51 de la carta.

128 González Campos, J.; Sánchez Rodríguez, L. y Andrés Sáenz de Santa María, M., Curso..., cit., p. 902.

129 Cabe recordar los bombardeos de 1986 sobre las ciudades libias de Trípoli y Bengasi, en respuesta a un atentado terrorista en una discoteca de Berlín, o el ataque con misiles contra un cuartel en Bagdad (Iraq) en 1993 después de dos meses de un presunto intento de asesinato del ex presidente Bush. 
Pickering, declaró que no se trataba de una represalia, sino de una operación encaminada a impedir nuevos ataques terroristas contra objetivos estadounidenses.

Tras los atentados del 11 de septiembre, Estados Unidos de América invocó nuevamente la legítima defensa para actuar militarmente en Afganistán, pero esta intervención no se ajustaba al artículo 51 de la carta, sino que constituía un caso de defensa propia preventiva y, por tanto, un supuesto ilegítimo del uso de la fuerza armada en tanto que se prescindió del Consejo de Seguridad. En consecuencia, la Estrategia de Seguridad Nacional se limita a oficializar la institución de la defensa preventiva como medio de combate para defender los intereses nacionales.

\section{EL TRÁNSITO DEL MULTILATERALISMO AUTORITARIO AL UNILATERALISMO AGRESIVO}

Como observa Del Arenal, "el derrumbamiento de la Unión Soviética, la desaparición del bloque comunista y el triunfo de la democracia y la economía de mercado eliminó la fractura dominante y el enfrentamiento Este-Oeste, siendo sustituida por fracturas hasta ahora consideradas como menores o secundarias. Paralelamente a ello, desapareció el férreo control que las superpotencias ejercían antes sobre los actores secundarios, multiplicándose sus márgenes de autonomía y con ello las posibilidades de conflicto". ${ }^{130}$ Empero, esta circunstancia ha conllevado el que estemos "pisando un alba nueva, cuya luz a Garcilaso se le antojaba dudosa. Un nuevo orden en el que aparte del monopolio del poder por uno solo, opera la renuencia exclusivamente por una lectura unilateral y, a veces, parroquial". 131

Un alba nueva en la que, según Chomsky "surge una determinación declarada de gobernar el mundo por la fuerza, única dimensión en que es hegemónica la potencia estadounidense, y de asegurarse de que no surgirá ningún desafío a su dominio. Se declararán, pues, guerras preventivas a voluntad". ${ }^{132}$ La actual política exterior de los Estados Unidos de Amé-

130 Arenal, C. del, "La nueva sociedad mundial y las nuevas realidades internacionales: un reto para la teoría y para la política", Cursos de derecho internacional y relaciones internacionales de Vitoria Gasteiz, Bilbao, 2001, p. 27.

131 Morán, F., Tiempo de reformas, Madrid, 1999, p. 13.

132 Chomsky, N., "Graves preocupaciones", La Vanguardia, 22 de marzo del 2003. 
rica - y recuérdese que, como decía Maquiavelo, ${ }^{133}$ la política la hacen los hombres, con sus pasiones, su temperamento y sus fantasías - no tiene presente que las decisiones de una única potencia no pueden sustituir el sistema de seguridad colectiva previsto en la carta. En la época de la guerra fría e incluso durante la etapa de distensión, la bipolaridad - resultante de la existencia de dos potencias hegemónicas - ayudaba a evitar los extremos y los posibles desequilibrios, promoviendo compromisos entre Estados Unidos de América y la URSS. En el mundo unipolar la situación descrita no tiene lugar y ahora, sin el contrapeso soviético, la superpotencia ha retomado "la diplomacia de las cañoneras" y el multilateralismo resultante del espíritu de Reykiavik y la caída del Muro de Berlín fue el sueño de una noche de verano.

Afirma el ex presidente Clinton que hay que "destacar el acierto de las respuestas multilaterales en los lugares conflictivos del mundo. Las naciones que cooperan, con la mediación de Naciones Unidas, se dividen los costes y las responsabilidades durante dichas operaciones, minimizan el resentimiento contra Estados Unidos de América y sientan las bases de valiosas pautas de colaboración. En un mundo cada vez más interdependiente, deberíamos optar por esa vía siempre que sea posible", ${ }^{134}$ mientras que su secretaria de Estado, Albright, matiza ante el Senado de su país que "el liderazgo de Estados Unidos de América en el marco de instituciones colectivas exige lo que llamaría multilateralismo autoritario, [es decir] que, cuando Estados Unidos de América actuaba con otros, debíamos ser quienes estableciéramos los objetivos y garantizáramos el éxito". ${ }^{135}$ Posteriormente, a partir del 11 de septiembre los Estados Unidos de América iniciaron toda una serie de actuaciones unilaterales que, junto con el nuevo documento estratégico de seguridad nacional aprobado en septiembre del 2002 por el presidente Bush, sientan las bases del que podría denominarse orden imperial estadounidense. ${ }^{136}$ Así, pues, la respuesta de la política exterior estadounidense a los atentados no fue girar hacia el unilateralismo, en el cual ya se encontraba instalada, sino pasar a un unilateralismo extremo, esto es, más agresivo. A partir del 11 de

133 Maquiavelo, N., "Informe de los asuntos de Alemania", Escritos politicos, Madrid, 1991.

134 Clinton, B., Mi vida..., cit., p. 753.

135 Albright, M., Memorias..., cit., p. 216.

136 Al respecto, Ferguson, N., Cplossus: the price's of America's Empire, Nueva York, 2004. 
septiembre cabe hablar de un antes y un después ${ }^{137}$ en tanto que marcaron una radicalización del unilateralismo: el multilateralismo autoritario se transformó en unilateralismo agresivo, ${ }^{138}$ tal como se desprende de las palabras de la consejera para asuntos de seguridad nacional, Condolezza Rice, ${ }^{139}$ al escribir que el multilateralismo no puede encorsetar la actuación de Estados Unidos de América ni impedir la defensa del interés nacional y, por ello, frente al idealismo de la administración Clinton se opone el realismo de la administración Bush.

Empero, además, el unilateralismo comporta el descrédito estadounidense frente a los otros Estados. En los días de la crisis de los misiles soviéticos en Cuba, el secretario de Estado estadounidense Dean Acheson recibió el encargo de informar sobre la situación a Charles De Gaulle. Tras informarle, Achenson le dijo que tenía fotografías de los misiles y quería mostrárselas. El presidente francés le contestó que no hacía falta, pues "la palabra del presidente me basta". Como ha quedado patente con la crisis abierta en Iraq por el presidente Busch Jr., su palabra ya no es suficiente para la inmensa mayoría de los líderes mundiales y todos le han solicitado que mostrase las pruebas. En consecuencia, como afirma Brzezinski, asesor de seguridad nacional del ex presidente Carter, en el papel y posición de los Estados Unidos de América en el mundo actual se da la siguiente inquietante paradoja: "el poder estadounidense está en su cenit histórico. Pero la posición política global de EUA está en su sima", ${ }^{140}$ pues en los casos de uso de la fuerza protagonizados por los Estados Unidos de América en Kosovo (1999), Afganistán (2001) e Iraq (2003) han sido calificados de intervenciones unilaterales y contrarios a la legalidad internacional. Y ante esta situación salta la siguiente pregunta ies el derecho internacional una amenaza para los Estados Unidos de América?

137 Al respecto, Daalder, I. y Lindsay, J., America unbound: the Bush revolution in foreign policy, Washington, 2003.

138 Prueba de ello son, por ejemplo, la Estrategia de Seguridad Nacional (White House, The National Security Strategy of the United States, Washington, septiembre del 2002) y la Estrategia Nacional para Combatir el Terrorismo que contiene cuatro objetivos: 1) Destruir a los terroristas; 2) Impedir que los terroristas tengan financiación y refugios en Estados; 3) Evitar que el terrorismo encuentre Estados débiles en los que propagar sus ideas y 4) La defensa de los ciudadanos e intereses estadounidenses dentro del país y en el extranjero (White House, National Strategy for Combating Terrorism, Washington, 2003, pp. 15 y ss.).

139 Rice, C., "Promoting the national interest", Foreign Affairs, 2000, núm. 1, pp. 45 y ss.

140 Brzezinski, Z., "La seguridad de EEUU en un mundo unipolar", PE, 2004, núm. 97, p. 58. 
Después de los ataques del 11 de septiembre parecía que había llegado el momento del multilateralismo y la hora de reforzar el papel de las Naciones Unidas: "en un primer momento se abrieron expectativas de cambio en la actitud internacional de EUA: del anterior unilateralismo se pasó a asumir la necesidad de crear una gran coalición internacional, necesariamente heterogénea, y por tanto, integrada por aliados muy diversos con puntos de vista divergentes sobre muchos aspectos". ${ }^{141}$ La realidad era que los Estados Unidos de América habrían podido liderar el sistema multilateral, cuyo eje son las Naciones Unidas, frente al terrorismo, pero la verdad es otra muy distinta: la postura estadounidense ha acentuado el unilateralismo exhibido durante los últimos tiempos con el fin satisfacer sus intereses o combatir las amenazas a su seguridad, y tal postura recuerda el famoso "I believe in God and in the American way of life", con el que respondía Superman a la pregunta de "What do you believe in?".

Los atentados del 11 de septiembre proporcionaron el empujón necesario a la voluntad política de Estados Unidos de América para imponerse en su afán de influencia y dominación de la sociedad internacional. A partir de entonces, bajo el manto de la denominada seguridad nacional, la misión de los Estados Unidos de América es combatir el eje del mal, compuesto por Iraq, Irán y Corea del Norte, acusados de almacenar armas nucleares y fomentar el terrorismo. ${ }^{142}$ Empero, esta misión es el medio para conseguir la hegemonía de los Estados Unidos de América en una era unipolar, objetivo último de la administración Bush. El fundamento de esta hegemonía sería el siguiente: Estados Unidos de América debe mantener su primacía internacional en beneficio del mundo, pues es el único Estado, entre todos los Estados, que se define por un conjunto de valores políticos y económicos universales: libertad, democracia, igualdad, derechos humanos, propiedad privada y mercado (según Huntington). Y, en atención a tal circunstancia, el fin trascendente de los Estados Unidos de América es establecer una igual libertad en América y

141 García Pérez, R., "Relaciones transatlánticas. Después del 11-S”, Politica Exterior, 2002, núm. 86, p. 26.

142 Según Ibáñez Muñoz, “algunos regímenes se han resistido y se resisten a aceptar las condiciones de la pax americana, por lo que el gobierno estadounidense los ha señalado como Estados díscolos (rogue states) o miembros de un eje del mal” (Ibáñez Muñoz, J., "El desafío a la pax americana desde el 11 de septiembre de 2001", El imperio inviable, Madrid, Tecnos, 2004, p. 36). 
por añadidura en el resto del mundo, ya que la arena en la que los Estados Unidos de América deben defender y promover sus fines es la arena mundial (según Morgenthau). ${ }^{143}$

Escribe Del Arenal que, tras el fin de la guerra fría, "la seguridad nacional y la seguridad mundial están totalmente interrelacionadas y hoy son en la práctica la misma cosa". Y lleva razón este autor. Ahora bien, la realidad que plasma esta afirmación debe ser entendida en sus propios términos y no ser objeto de una interpretación torticera, como la que realiza actualmente Estados Unidos de América dependiendo de sus exclusivos intereses nacionales. Como apunta este mismo autor, la mentada interrelación significa que "la seguridad nacional en el mundo de hoy ya no puede lograrse unilateralmente o a expensas de otros Estados. En un mundo interdependiente sólo a través de la seguridad mundial de todos es posible el objetivo legítimo de la seguridad nacional. El reconocimiento de esta interdependencia significa que los Estados deben organizar su seguridad en cooperación. Seguridad nacional y seguridad global son, así, las dos caras de una misma moneda". ${ }^{144}$

En el caso de Afganistán, tras la faz de la legítima defensa invocada, puede advertirse que "la operación militar de Estados Unidos de América (y sus aliados) es la venerable autotutela o autodefensa, la institución en cuya virtud cada Estado, por sí o mediante las oportunas alianzas, persigue la satisfacción de sus intereses, recurriendo eventualmente a la fuerza armada". ${ }^{145}$ Por ello, si bien es cierto que el 11-S dio autoridad moral para intervenir a los Estados Unidos de América, ${ }^{146}$ esta intervención debería haberse realizado en el marco de las Naciones Unidas que, como afirma Jacques Chirac, "es el único legítimo para construir la paz en todas partes". ${ }^{147}$ Por consiguiente, la actuación estadounidense responde a $s u$ interpretación de la interrelación entre seguridad nacional y mundial. Sin embargo, como escribe el antiguo embajador para asuntos terroristas de los Estados Unidos de América, Wilcox, "el uso de la fuerza armada... aunque políticamente popular, es un método ineficaz y contraproducente contra

\footnotetext{
143 Citados en Chomsky, N., El nuevo orden mundial (y el viejo), Barcelona, 2003, pp. 42 y 43.

144 Arenal, C., "El nuevo escenario mundial y la teoría de las relaciones internacionales", Hacia un nuevo orden internacional y europeo. Estudios en homenaje al profesor Don Manuel Díez de Velasco, Madrid, 1993, pp. 87 y 88, respectivamente.

145 Remiro Brotóns, A., Estados..., cit., p. 119.

146 Armacost, M., "La política exterior de EEUU después del 11-S”, Política Exterior, 2002, núm. 86, p. 77.

147 La Vanguardia, 21 de marzo del 2003.
} 
el terror. EUA debería diseñar una estrategia más sofisticada, que incluya el fortalecimiento de los métodos tradicionales del contraterrorismo, reservando el uso de la fuerza como una opción limitada". ${ }^{148}$

La consideración transcrita tiene plena validez para la lucha terrorista en el plano internacional. En primer término, poner a disposición de la justicia a los autores de los actos terroristas. Circunstancia puesta de manifiesto en las Resoluciones 1269 (1999), 1368 (2001) y 1373 (2001): todos los Estados tienen que velar por que toda persona que participe en la financiación, planificación, preparación o comisión de actos de terrorismo o preste apoyo a esos actos sea sometida a la acción de la justicia. Esta afirmación, contenida en la Resolución 1373 (2001), "puede convertirse en el agente catalizador que precipite el final de un proceso que nos llevaría (o muy cerca) a la afirmación de que, en efecto, parece estar cuajando una norma de derecho internacional general que obligaría a todo Estado con posibilidad de hacerlo a perseguir, procesar o extraditar, sin inmunidad de jurisdicción que valga incluso por la cualidad de órgano de un Estado del culpable, a las personas autores de ciertos crímenes internacionales, en nuestro caso, terrorismo". ${ }^{149} \mathrm{Y}$ si fuera indispensable, siempre dentro de la legalidad internacional, la utilización de las medidas necesarias, incluida la relativa al uso de la fuerza, para reaccionar y, en su caso, castigar a los autores de actos terroristas, ya sean organizaciones o Estados.

En fin, en el documento Estratégico de Seguridad Nacional de agosto de 1991 se proclamaba que "tenemos al alcance de nuestra mano una extraordinaria posibilidad que pocas generaciones han disfrutado: edificar un nuevo sistema internacional conforme con nuestros propios valores e ideales", ${ }^{150}$ y el borrador sobre seguridad nacional (defence policy guidance), elaborado en marzo de 1992, contenía el siguiente pasaje: Estados Unidos de América "debe estar en posición de actuar en forma independiente cuando no se logre impulsar la acción colectiva". ${ }^{151}$ Las afirmaciones contenidas en estos dos documentos han pasado de la teoría a la práctica con motivo de la crisis y conflicto armado en Iraq (2003); esto es, la diplomacia de los Estados Unidos de América ha fracasado en su intento de liderar una acción colectiva legitimada por el Consejo de

\footnotetext{
148 Wilcox, P., "Luchar contra el terror”, Política Exterior, 2001, núm. 84, p. 13.

149 Gutiérrez Espada, C., “No cesaréis...”, cit., p. 28.

150 National Security Strategy of the United States, agosto de 1991, p. V.

151 Citado en Remiro Brotóns, A., Civilizados, bárbaros y salvajes en el nuevo orden internacional, Madrid, 1996, p. 183.
} 
Seguridad y, por consiguiente, ha decidido actuar de forma independiente - careciendo del sentido de interdependencia y adaptación, esencial para la vida en cualquier sociedad - y llevar a cabo una acción unilateral del uso de la fuerza armada.

\section{CONSIDERACIONES FINALES}

Los atentados terroristas perpetrados en Nueva York y Washington el día 11 de septiembre del 2001 marcan un punto de inflexión tanto en la lucha internacional contra el terrorismo como en la figura de la legítima defensa. Así, en la Resolución 1368 (2001), de 12 de septiembre —adoptada unánimemente-, el Consejo de Seguridad se manifestó decidido a tomar todas las medidas necesarias para responder a los ataques terroristas y combatirlos en todas sus formas de conformidad con las funciones atribuidas por la Carta de las Naciones Unidas. Desde el punto de vista del denominado derecho a la legítima defensa, la Resolución 1368 (2001) contiene dos extremos esenciales: el reconocimiento del derecho inmanente a la legítima defensa individual o colectiva de conformidad con la carta y la utilización del término ataques - y no el de "atentado - respecto de las acciones terroristas perpetradas el 11 de septiembre. Ahora bien, debe observarse que en el caso de las acciones armadas contra el régimen de los talibanes el Consejo de Seguridad no ha procedido a autorizar el uso de la fuerza, limitándose a incluir en el preámbulo de la Resolución 1368 (2001) un ambiguo reconocimiento del derecho inmanente de legítima defensa individual o colectiva de conformidad con la Carta de las Naciones Unidas.

$\mathrm{Al}$ tenor del derecho internacional vigente en el momento de los atentados terroristas del 11 de septiembre, no cabe el derecho de legítima defensa por parte de los Estados Unidos de América contra Afganistán, pues a éste último no le ha sido imputada la autoría (ni agresión directa ni indirecta) del ataque que tampoco es "armado". El Consejo de Seguridad no califica los actos terroristas como "ataques armados", mientras que sí los califica de amenaza a la paz internacional. El afirmar la existencia de legítima defensa en el caso analizado, conlleva una desnaturalización del concepto de esta institución previsto en el artículo 51 de la carta, que es lo que parece haber ocurrido tras el 11 de septiembre: una ampliación del concepto de legítima defensa individual o colectiva para los casos más graves de terrorismo. Ahora bien, de ser cierta esta posibilidad, se trata de una ampliación del derecho 
de legítima defensa no prevista ni aceptada, salvo por un número muy reducido de Estados (Estados Unidos de América, Israel, África del Sur).

Después de los ataques del 11 de septiembre, parecía que había llegado el momento del multilateralismo y la hora de reforzar el papel de las Naciones Unidas, pues los Estados Unidos de América habrían podido liderar el sistema multilateral, cuyo eje son las Naciones Unidas, frente al terrorismo, pero la verdad es que la postura estadounidense ha acentuado el unilateralismo exhibido durante los últimos tiempos en orden a satisfacer sus intereses o combatir las amenazas a su seguridad. Los mentados atentados del 11 proporcionaron el empujón necesario a la voluntad política de Estados Unidos de América para imponerse en su afán de influencia y dominación de la sociedad internacional. A partir de entonces, bajo el manto de la denominada seguridad nacional, la misión de los Estados Unidos de América es combatir el eje del mal, compuesto por Iraq, Irán y Corea del Norte, acusados de almacenar armas nucleares y fomentar el terrorismo. Empero, esta misión es el medio para conseguir la hegemonía de los Estados Unidos de América en una era unipolar.

En el caso de Afganistán, tras la faz de la legítima defensa invocada, puede advertirse que la operación militar de Estados Unidos de América es la autotutela, la institución en cuya virtud cada Estado, por sí o mediante las oportunas alianzas, persigue la satisfacción de sus intereses, recurriendo eventualmente a la fuerza armada. Por ello, si bien es cierto que el 11 de septiembre dio autoridad moral para intervenir a los Estados Unidos de América, esta intervención debería haberse realizado en el marco de las Naciones Unidas, que es el único organismo institucional legítimo para construir la paz en todos los rincones del planeta, y no utilizando la figura de la legítima defensa preventiva. Figura esta última que se ha convertido en el eje central de la estrategia de seguridad nacional estadounidense. 